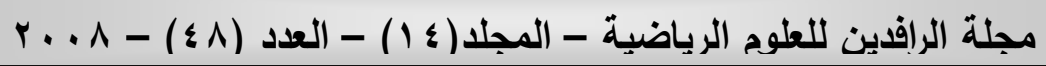

انتقال اثر التعلم العمودي وإلعمودي المعكوس باستخدام

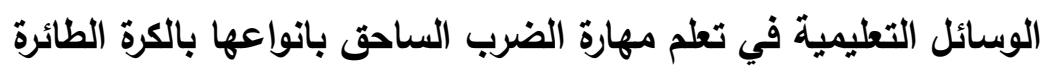

أ. د. محمد خضر اسمر الحياني م. د. خالد محمد داؤد البنا م . د احمد حامد احمد

جامعة الموصل /كلية التربية الرياضية

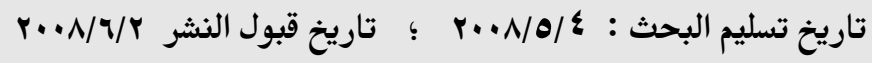

الملخص

يهدف البحث إلى الكثف عما يلي :- التقال

1- انتقال اثر التعلم العمودي باستخدام الوسائل التعليمية من المهمة السهلة الى المهمة الصعبة

وبالعكس في تعلم مهارة الضرب الساحق بأنواعها بالكرة الطائرة .

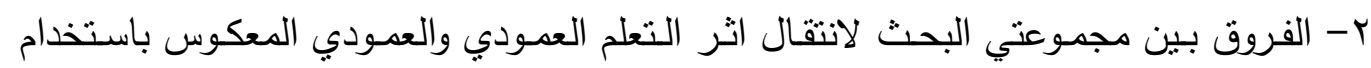

الوسائل التعليمية في مهارة الضرب الساحق بانواعها بالكرة الطائرة .

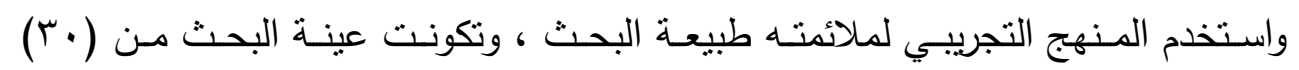

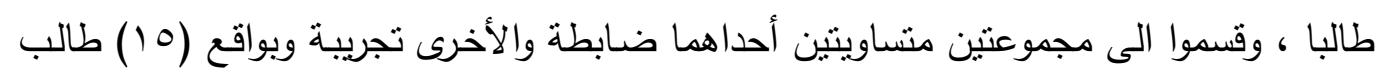
لكل مجموعة ، وتم تحقيق التكافؤ بين مجموعتي البحث في متغيرات (العمر والطول والكنلة

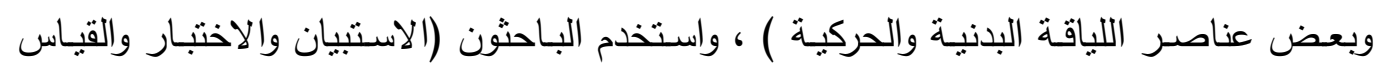

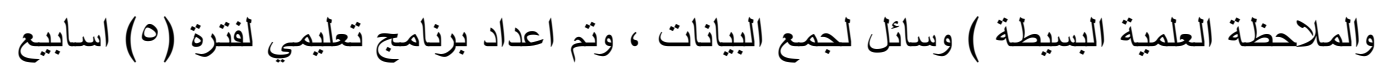

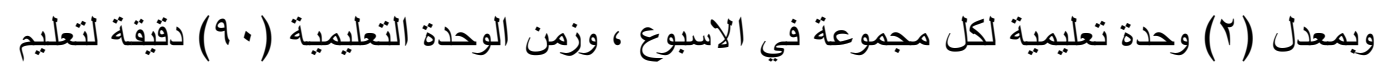

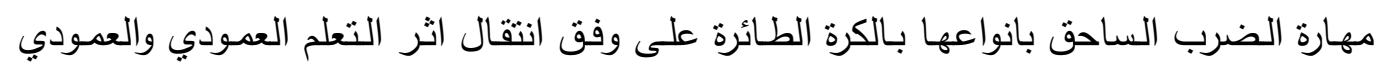

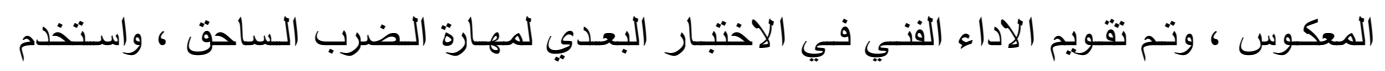
(الوسط الحسابي والانحراف المعياري واختبار " ت" وسائل لمعالجة البيانات إحصائيا ، واستتنج

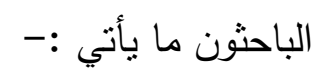
1- حققت المجموعة الضابطة التي بدات بالمهمة السهلة ثم الصعبة ( العمودي ) والمقرون

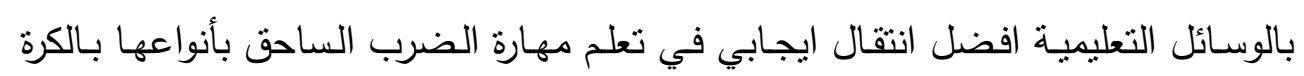
الطائرة مقارنة مع المجموعة التجريبية وفي جميع معايير انتقال اثر التعلم . 


$$
\begin{aligned}
& \text { Y- حققت المجموعة التجريبيـة التي بـأت بالمهــة الصعبة ثم السهلة (العمودي المعكوس) }
\end{aligned}
$$

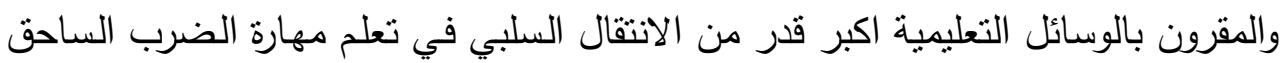

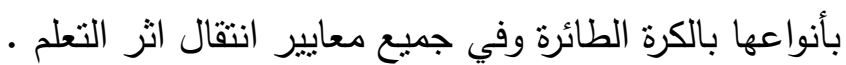

$$
\begin{aligned}
& \text { r- وجود فروق ذات دلالة معنوية بين مجموعتي البحث ولمصلحة المجموعة الضابطة التي } \\
& \text { بدات بالمهمة السهلة ثم الصعبة (العمودي ). }
\end{aligned}
$$

\title{
Abstract \\ "The Transfer of the effect of vertical and inverted vertical learning by using learning tools in learning the skill of sstrike in Volley Ball"
}

\author{
ProF. Dr. Mohammed K. Assmer Al-Hayane \\ Dr. Khalid M. Dawood Al-Bana \\ Dr. Ahmed H. Ahmed Al-Sowedi \\ University of mosul/College of Physical Educations
}

Research aims to uncover the follows :

1- Shifting the effect of the vertical learning by using the educational methods from the easy task to the hard one and vice versa of the finishing stroke styles in volley ball .

2- Differences between the research's groups to change the effect of the vertical learning and the inverted one by using the educational methods of the finishing stroke styles in volley ball.

The experimental method was used to fit the nature of the research. " That the sample was of 30 students divided into two equal groups (15 in each one).

The first one was regular and the other was experimental ", and then to achieve equivalence between them in the variables (age, height, size, and some elements of physical and motional fitness ), and the researchers used (questionnaire, test, measurement and simple scientific observation) ways to collect data . Educational program was prepared for (5) weeks , (2) educational unit for each group per a week and (90) minute for each unit for teaching the skill of finishing stroke styles in 
volley ball in regard with shifting the effect of vertical and inverted learning. The technical performance of the test was evaluated. The researchers used (arithmetic mean, Standard deviation and titest ) as means to process the data statistically and they concluded the following :

1- The regular group which started with the easy task before the hard one (the vertical education accompanied with the learning methods) achieved the best positive shift of learning overwhelming beat styles comparing with the experimental group in every standard .

2- There were significant differences between the two groups of the research for the interest of the of the regular group which started the easy before the difficult task vertically .

ا 1 - المقدمة واهمية البحث :

اثبـت التحليل العلمسي تطورا كبيرا في مجال التعلم الحركي من اجل تهيئة المواقف

التعليميـة بشكل يستثير دوافع المتعلم والوصـول الى الهدف من العملية التعليميـة ، وقد برزت ظاهرة انتقال اثر التعلم في المجال الرياضـي كاحد الفلسفات التعليميـة الحديثة والتي اعطت مـردودات ايجابيـة في فن الاداء والانجـاز الرياضـي ، فـالفرد عندما يـتعلم مهارة حركيـة فـان التغيرات التي تحدث في سلوكه يمكن الاستفادة منها في تعلم مهارات اخرى ، وعلى هذا الاساس فان التعلم السابق سينتقل الى التعلم الجديد وهو ما يسمى بانتقال التعلم " فعندما يكون الاداء الجديد فعالا فان النقل سيكون ايجابيا وعندما يكون الاداء الجديد ضعيفا بسبب تأثزه بالمعلومات المخزونة فان النقل سيكون سلبيا " (Mourice , 1997 , 10) ، ولكي يتحقق انتقال اثر التعلم الايجابي ينوجب نوفر شروط موضوعية تتعلق بالموضوع المراد تحقيق انتقال اثر التعلم فيه ، فضلا عن الشروط الذاتيـة التي تتعلق بـالفرد الذي ينتقل لايـه اثر التعلم الايجابي (سعودي ، 1997 ، r r ( ) ، اضافة الى ذلك " ان النقل يحدث بطريقتين، اولا بين الفعاليات المختلفة (النقل الجانبي او الافقي ) أي نقل المهارة من فعالية الى فعالية اخرى ، وثانيا داخل الفعالية الواحدة (النقل العمودي) فيعني نقل المهارة ضمن الفعالية الواحدة من الاسهل الى الاصعب " (محجوب الهب . (T) , Y... 6 
ان الانتقال من المهارات السهلة الى الصعبة او بالعكس وهو ما يسمى بالاتنقال حسب اتجاه

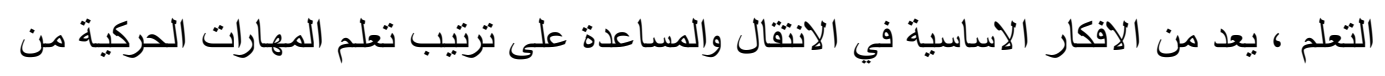

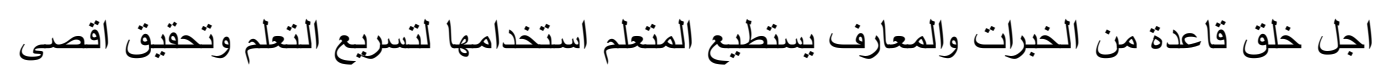

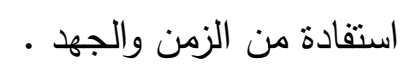

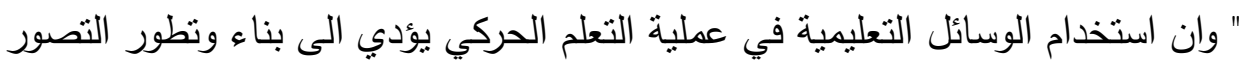

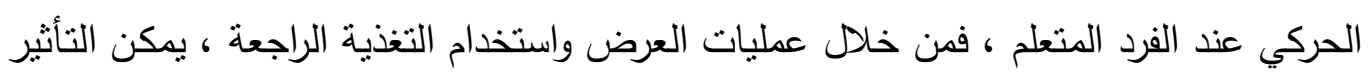

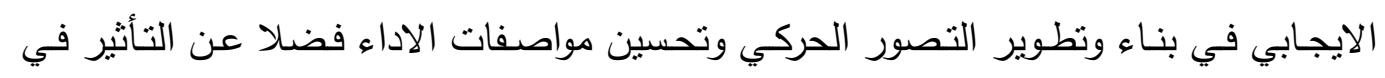

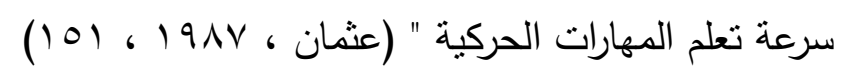

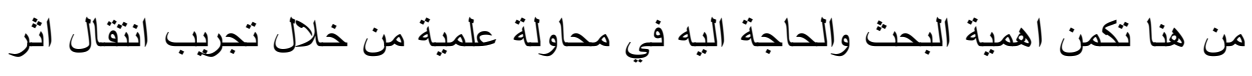

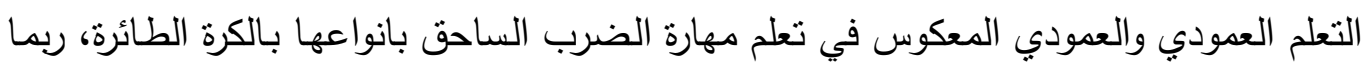

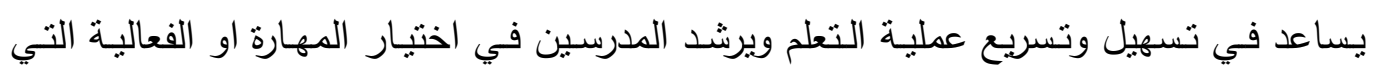
يبدأون بتعلمها على وفق مفردات مادة الكرة الطائرة المنهجية .

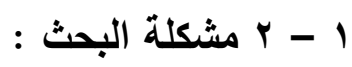

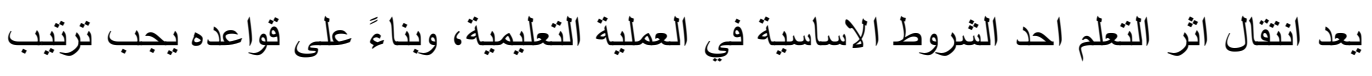

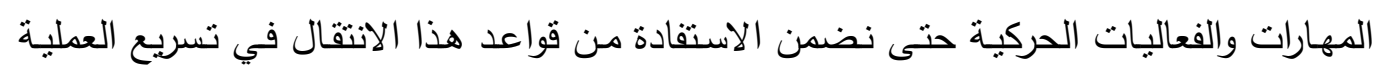

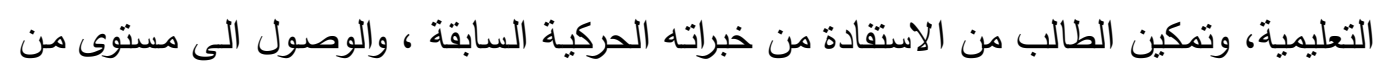

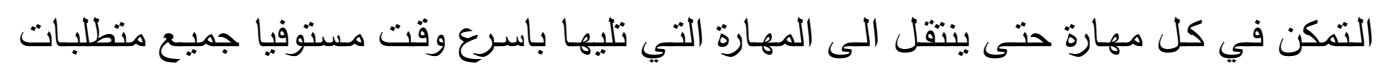

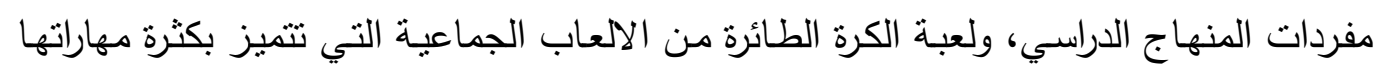

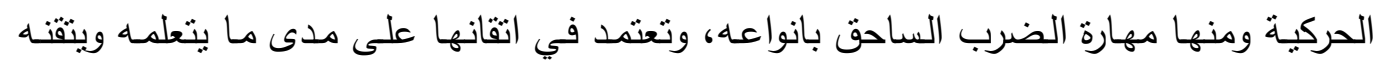

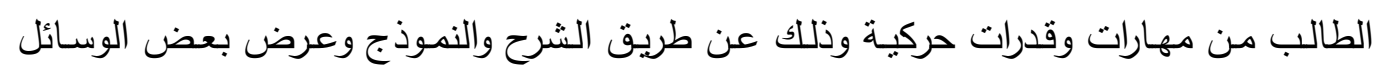

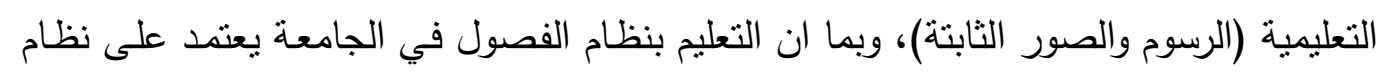

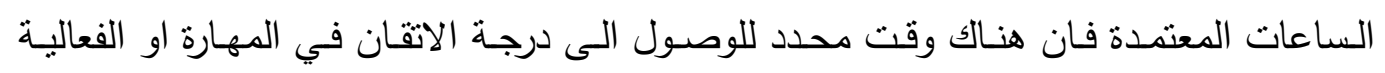

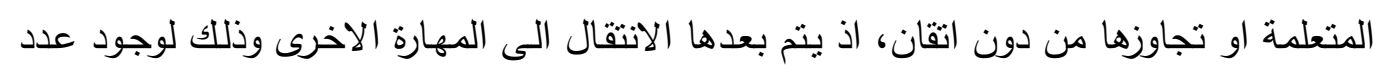

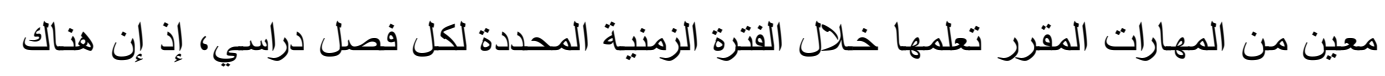

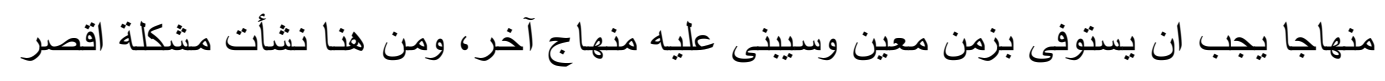

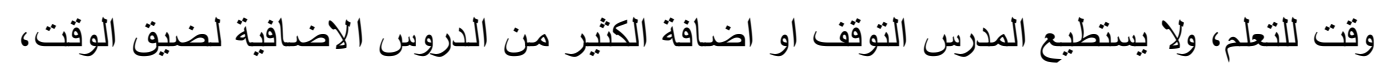

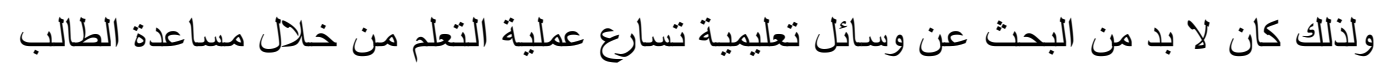

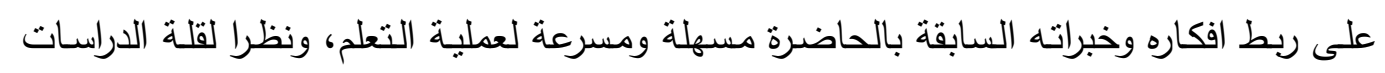
والابحاث التي اتجهت الى مجال ترتيب البدء بتعلم المهارات الحركية بالكرة الطائرة من المهارة 
السهلة الى الصعبة وبالعكس، لذا ارتأى الباحثان البدء بهذه الخطوة لدراسـة انتقال اثر التعلم العمودي والعمودي المعكوس في تعلم مهارة الضرب الساحق بانواعه لدى طلاب كلية التربية

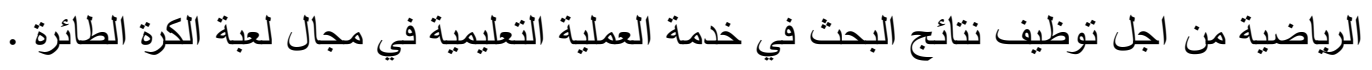

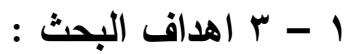

1-r-1-الكثف عن انتقال اثر التعلم العمودي باستخدام الوسائل التعليمية من المهمة السهلة

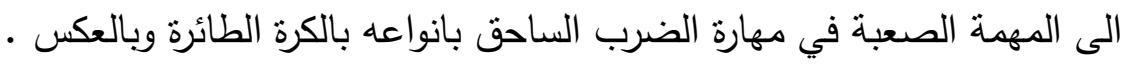

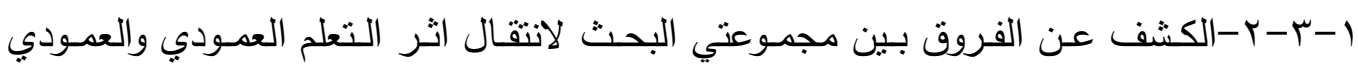

المعكوس باستخدام الوسائل التعليمية في مهارة الضرب الساحق بانواعه بالكرة الطائرة . : 1

**-انتقال اثر التعلم العمودي باستخدام الوسائل التعليمية افضل من انتقال اثر التعلم العمودي المعكوس باستخدام الوسائل التعليمية في مهارة الضرب الساحق بانواعه بالكرة الطائرة *- وجود فروق ذات دلالة معنوية بين مجموعتي البحث لانتقال اثر التعلم العمودي والعمودي المعكوس باستخدام الوسائل التعليمية في مهارة الضرب الساحق بانواعه بـالكرة الطائرة

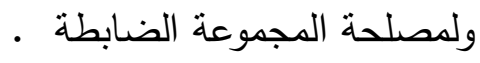

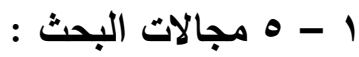

* المجال البشري : طلاب السنة الدراسية الثانية / كلية التربية الرياضية / جامعة الموصل .

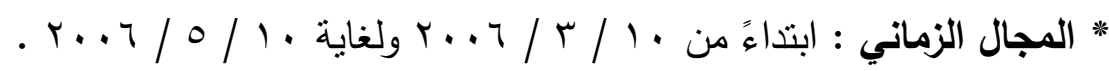
* المجال المكاني : القاعة الداخلية في فرع الالعاب الفرقية / كلية التربية الرياضية / جامعة المانة

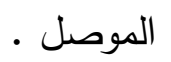

( 1 - 1

- انتقال اثر التعلم : هو تأثثر الممارسة السابقة لمهارات حركية او مفاهيم مكتسبة على تعلم

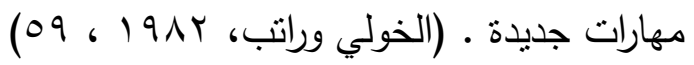

- ويعرفـه (Mourice) : بانـه استخدام تعلم سـابق او معلومـات سـابقة في اداء واجبـات او

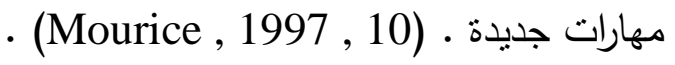

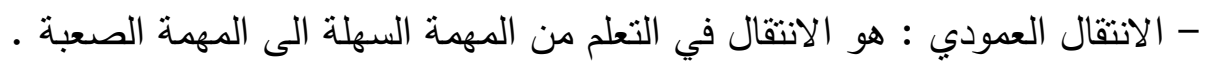

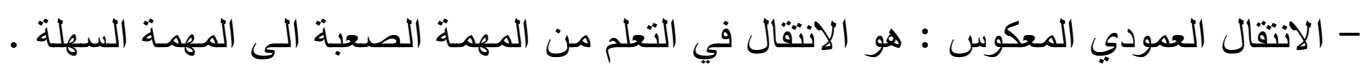

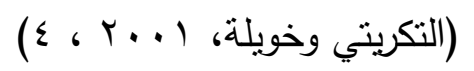

- المهارة (المهمة) السهلة : هي المهارة المتضمنة لحركة عدد قليل من مفاصل الجسم والتي تتطلب القليل من النوافق بين الاطراف . 
- المهارة (المهمة) الصعبة : هي المهارة التي تتطلب حركة العديد من اجزاء الجسم فضلا عن التوافق خلالها في الوقت نفسه (Schmidt, 1991, 283-287)

- الوسائل التعليمية : هي اجهزة وادوات ومواد يستخدمها المعلم لتحسين عملية التعليم والتعلم .

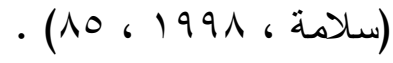

- مهارة الضرب الساحق بالكرة الطائرة : ويعرفها الباحثون اجرائياً بانها واحدة من اهم المهارات الاساسية الهجومية بالكرة الطائرة والتي تتطلب قدرة عالية بالتكنيك الحركي ومكونة من عدة انواع منها المواجه والخطاف وبالخداع ...

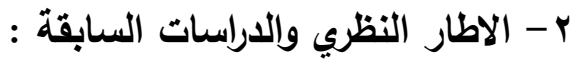

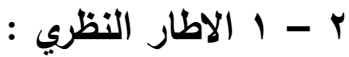
* معنى الانتقال :

هو تأثثر الخبرات والمعارف السابقة في تعلم المهارات الجديدة ، وقد يكون هذا التأثثر

$$
\text { ايجابي او سلبي او صفري، وللانتقال هدفان هما : }
$$

أ- الانتقال القريب : هو النقل الحادث بين المهام لفترات متقاربة كتغير المهارات او المواقف لاجل زيادة الدافع، او تعلم اجزاء صغيرة من المهارات في بداية البرنامج التعليمي لنقلها الى المهارات الاصعب والاكثر خطورة، كما يحدث في الجمناستلك في نعلم الحركات

$$
\text { وربطها مع الاداة . }
$$

ب- الانتقال البعيد : هو النقل بين مراحل النطور الحركي للانسان خلال حياته، فالطفل يتعلم المهارات الحركية لكيفية القفز او الرمي او الركض، وان اكتساب هذه الخبرات وهذا التعلم

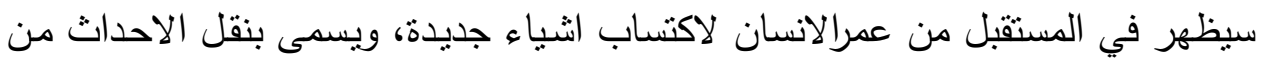

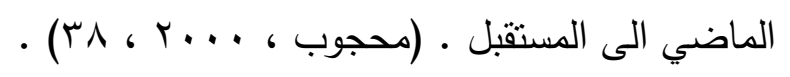

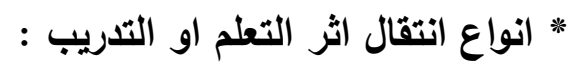

اولا : الانتقال حسب نتيجة التعلم ويقسم الى الانواع الاتية :

أ- الانتقال الايجابي : ويحدث عندما ييسر تعلم موقف تعلم موقف اخر (عثمان والثرقاي

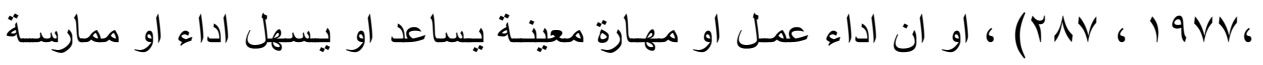

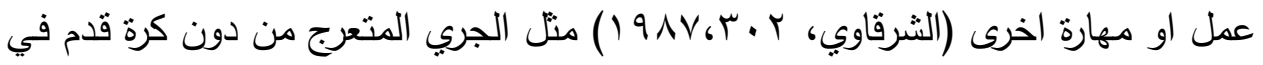

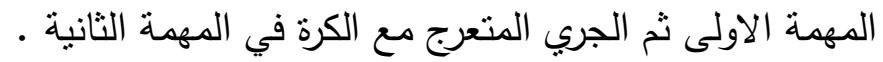

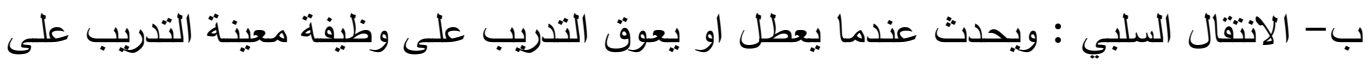

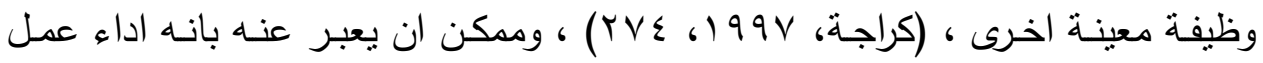

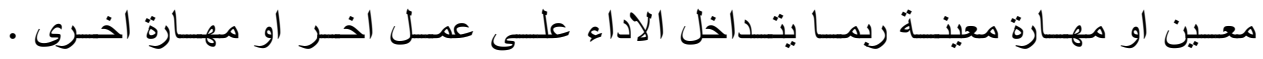




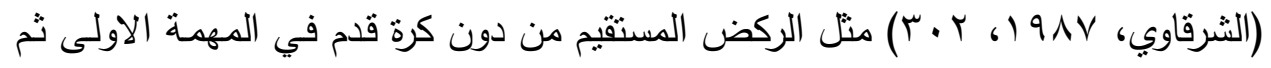

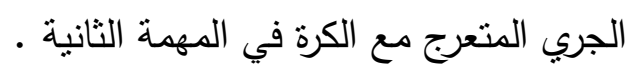

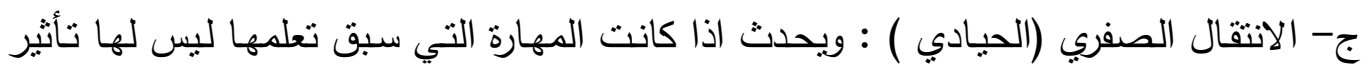

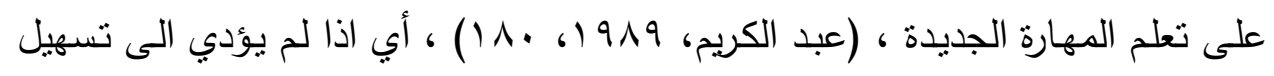

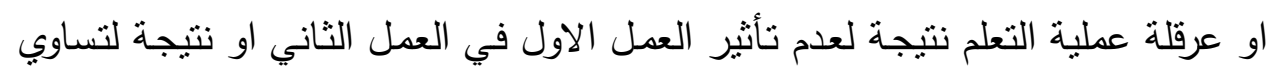

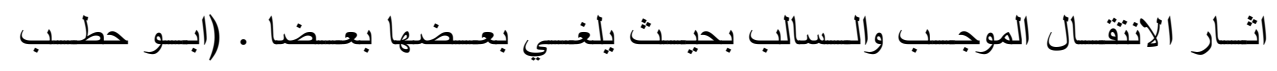

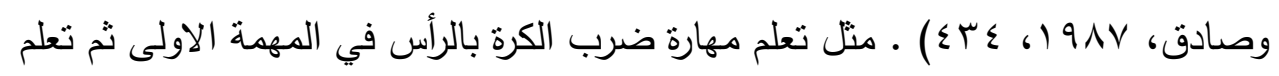
مهارة ضرب الكرة الثابتة بالقدم في المهمة الثانية . ثانيا : الانتقال حسب اتجاه التعلم ويقسم الى نوعين اساسيين هما :

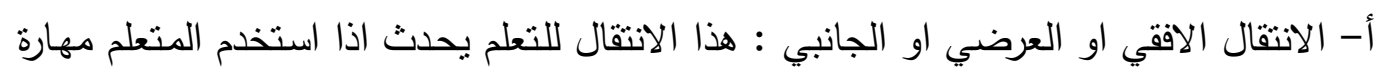

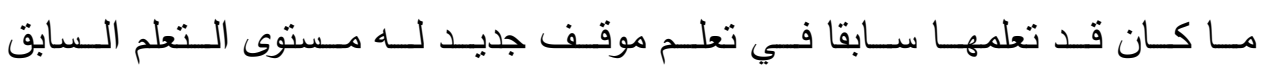

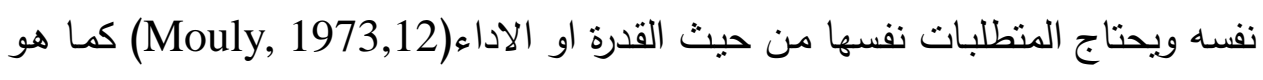

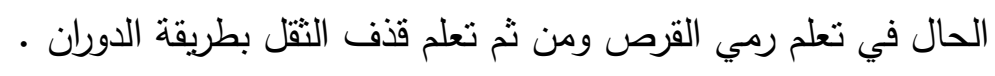

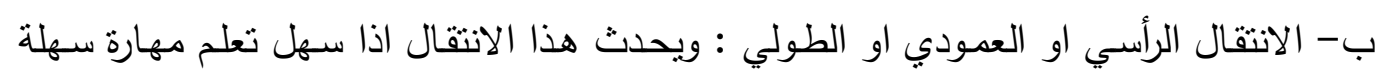

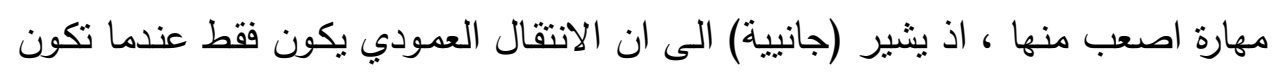

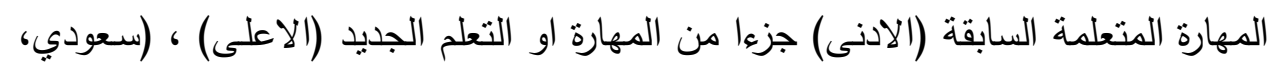

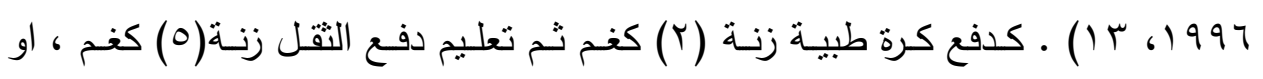

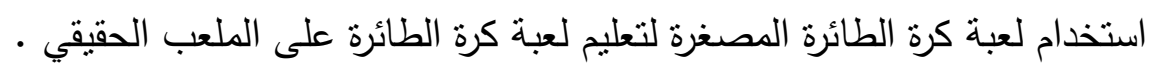
: الوسائل التعليمية : وهي بمعناها الثامل تضم جميع الطرائق والادوات والاجهزة والتتظيمات المستخدمة في نظام تعليمي بغرض تحقيق اهداف تعليمية محددة، اما دور الوسائل التعليمية في تحسين عملية

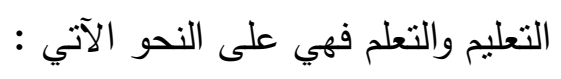

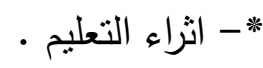

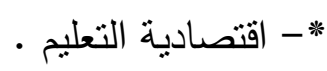

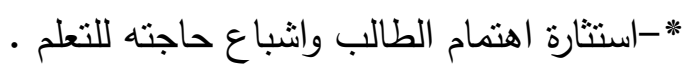

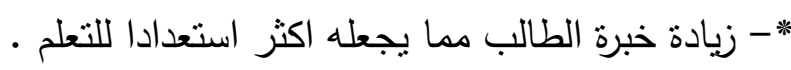

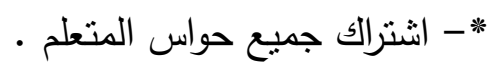

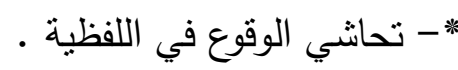

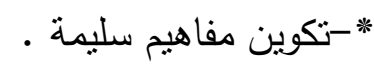
*- زيادة مشاركة الطالب الايجابية في اكتساب الخبرة . 


$$
\begin{aligned}
& \text { *-تتويع اساليب التعزيز التي تؤدي الى تثبيت الاستجابات الصحيحة . } \\
& \text { *- تتويع اساليب التعليم لمواجهة الفروق الفردية بين المتعلمين . } \\
& \text { *- ترتيب واستمرار الافكار التي يكونها الطالب . }
\end{aligned}
$$

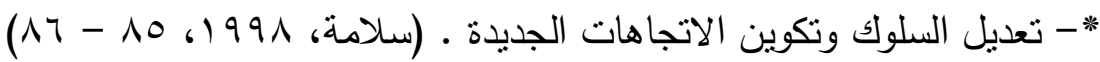

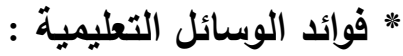

• التأثير الايجابي والفعال في بناء وتطوير التصور الحركي عند الفرد المتعلم .

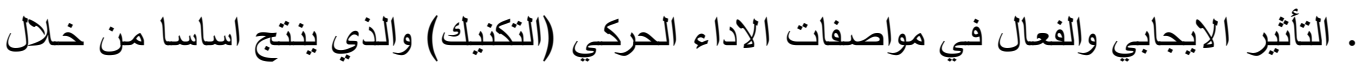

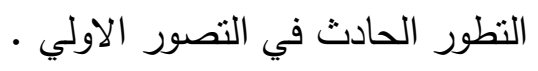

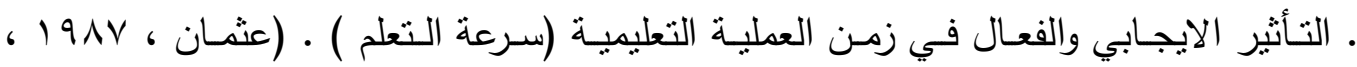

(10r

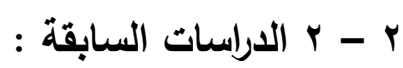

* * دراسة عامر محمد سعودي (1997) :

" دراسة انتقال أثر التعلم في بعض الحركات التمهيدية على اجهزة الجمناستك "

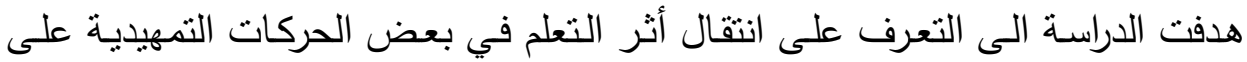

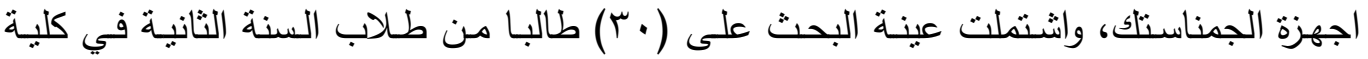
التربية الرياضية بجامعة الموصل، قسموا الى مجموعتين بواقع (10) طالب لكل مجموعة، وتم تحقيق التكافؤ بين المجموعتين في متغيرات العمر والطول والوزن وبعض عناصر اللياقة البدنية

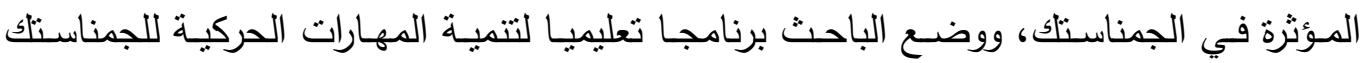
مستخدما الطريقة الجزئية بالاسلوب المتدرج في التعلم، اذ استغرق تتفيذ البرنامج (r (I) اسبوعا،

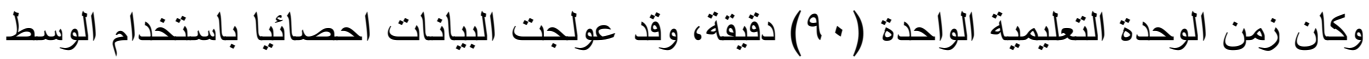

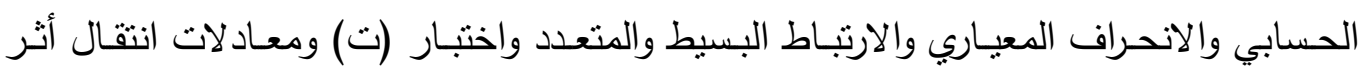

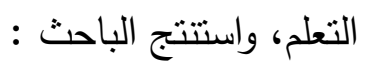

*- وجود فروق ذات دلالة معنوية في فن الاداء بين المجموعتين ولمصلحة المجموعة الاولى لئ

التي استخدمت حركات تخدم المهمة الثنانية .

*- عدم وجود فروق ذات دلالة معنوية في الاداء على الحركات الارضية فيما حققت المجموعة

الاولى نسب انتقال اكثر من الثانية ـ (سعودي ، 997 (1) .

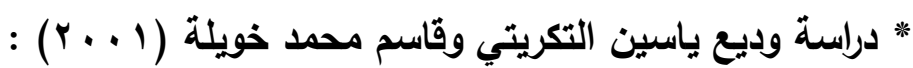

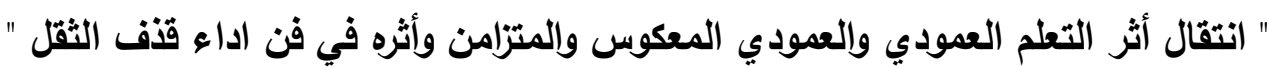

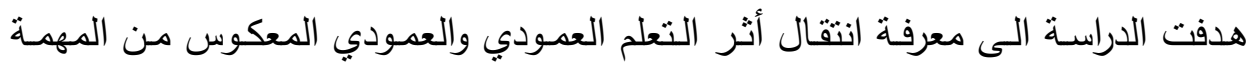

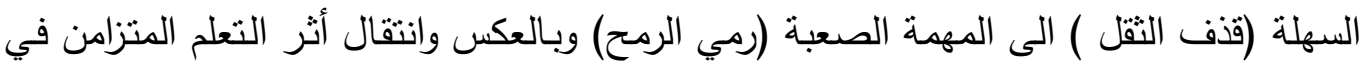


المهـات المتشابهة على مستوى فن الاداء في قذف الثقل، وتكونت عينة البحث من طلاب

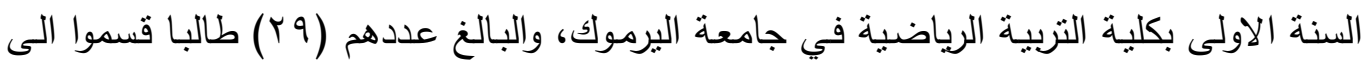

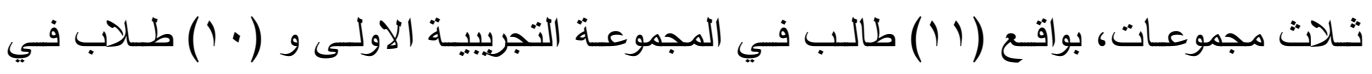
المجموعة التجريبية الثانية و (^) طلاب في المجموعة الضابطة، وتم تكافؤ مجموعات البحث

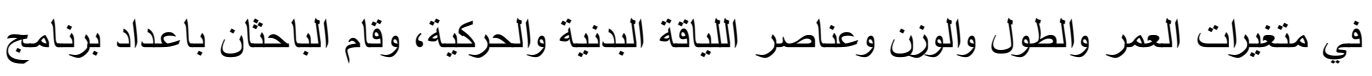

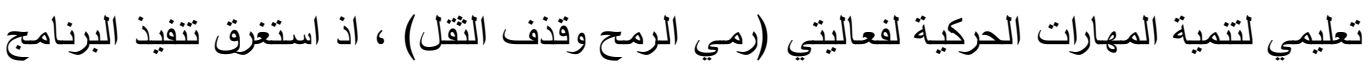

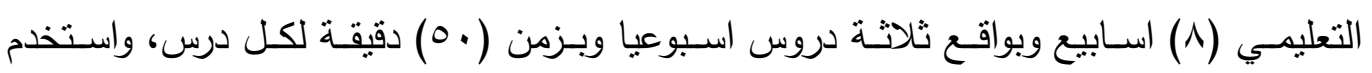

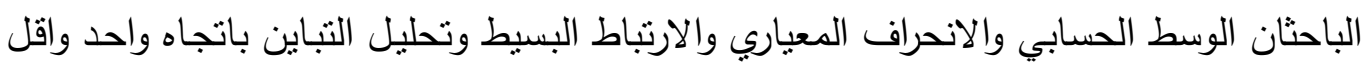

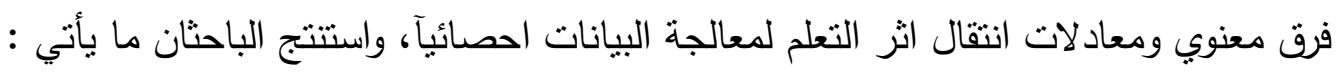

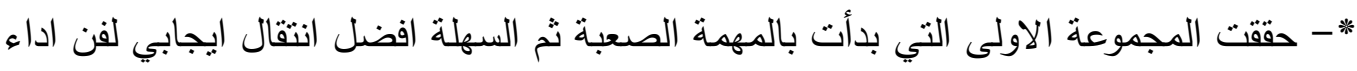
قذف النقل مقارنة مع المجموعتين الثانية والثالثة .

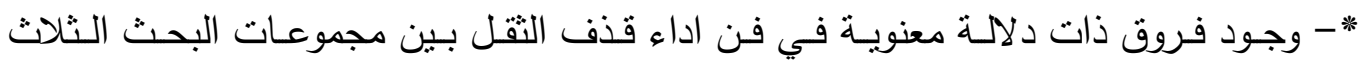

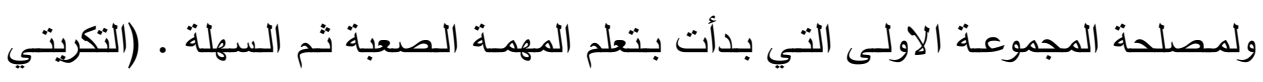

$$
\begin{aligned}
& \text { وخويلة ، (ب. (r) . } \\
& \text { r - اجراءات البحث : } \\
& \text { r - } 1 \text { منهج البحث : }
\end{aligned}
$$

استخدم الباحثون المنهج التجريبي لملائمته لطبيعة البحث .

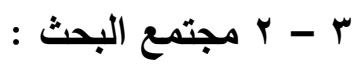

تم اختيار مجتمع البحث بالطريقة العمدية من طلاب السنة الدراسية الثانية بكلية التربية

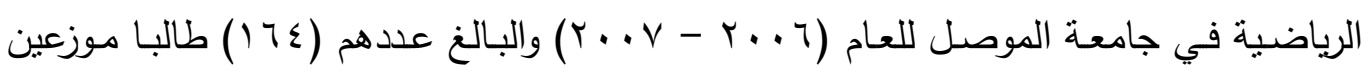
على (V) شعب . (V)

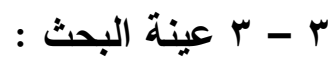

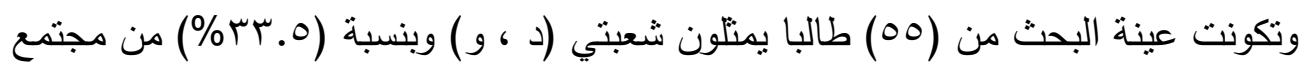

البحث، نم اختيارهم عشوائيا بطريقة القرعة من اصل (V) شعب ـ وقد استبعد من العينة الطلاب

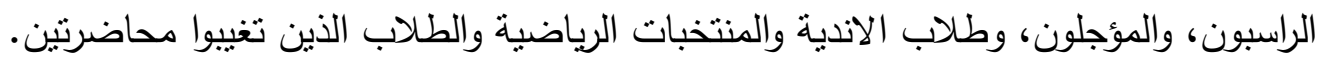

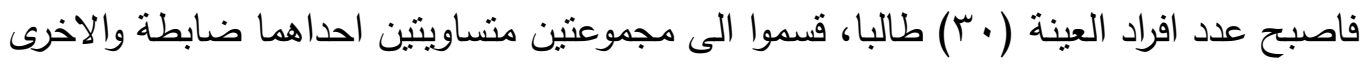


تجريبية وبواقع (0 (1) طالبا لكل مجموعة والجدول رقم (1) يبين ذلك

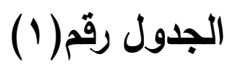

يبين عدد افراد عينة البحث والاساليب التعليمية المستخدمة

\begin{tabular}{|c|c|c|c|c|}
\hline عدد افراد العينة & المستبعد & عدد الطلاب & الاسلوب التعليمي & المجموعة \\
\hline 10 & Ir & rV & الانتقال العمودي س-ص" & الضابطة \\
\hline 10 & $1 \pi$ & $r_{\Lambda}$ & الانتقال العمودي المعكوس ص - & التجريبية \\
\hline$r$. & ro & 00 & \multicolumn{2}{|l|}{ المجموع } \\
\hline
\end{tabular}

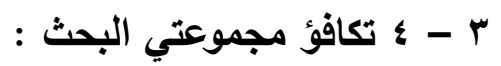

تمت عملية التكافؤ بين مجموعتي البحث لضبط المتغيرات الآتية :

*- العمر الزمني مقاسا بالسنة.

| - الطول مقاسا بالسنتيمتر.

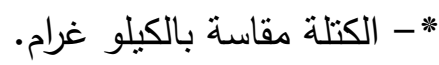

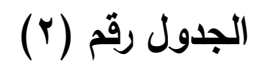

يبين دلالة الفروق بين مجموعتي البحث في متغيرات العمر والطول والكتلة

\begin{tabular}{|c|c|c|c|c|c|}
\hline \multirow{2}{*}{ قالمحسوية" } & \multicolumn{2}{|c|}{ التجريبية } & \multicolumn{2}{|c|}{ الضابطة } & \multirow{2}{*}{ تغيرات } \\
\hline & $\varepsilon n$ & س & $\varepsilon n$ & س- & \\
\hline $.0 \leqslant$ & $1 . r$ & 19.11 & $1 . \leqslant 9$ & $r . . r u$ & العمر / سنة \\
\hline . ro & \{.11 & 179.8 & $\varepsilon . r V$ & 179.1 & الطول / سم \\
\hline. .71 & $0 . r Y$ & 77. & T.rY & TV.VO & الكتلة / كفم \\
\hline
\end{tabular}

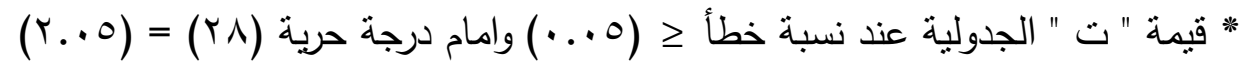

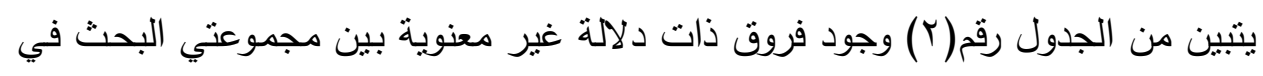

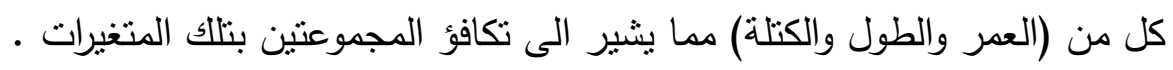

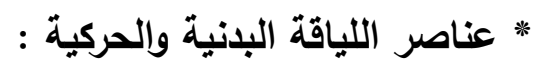

استخدم الباحثون اسلوب تحليل محتوى المصادر العلمية ذات العلاقة بموضوع البحث

لتحديد عناصر اللياقة البدنية والحركية الخاصة والمؤثرة في تعلم مهارة الضرب الساحق بانواعه

" س = مهارة سهلة ، ص = مهارة صعبة .

$1 \cdot 0$ 


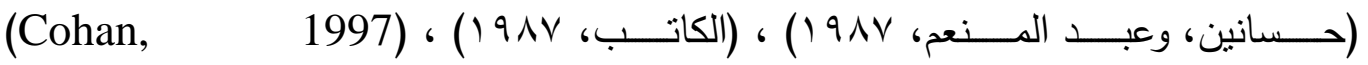

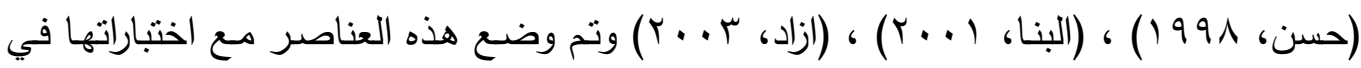
استبيان الملحق رقم (1) وعرضت على عدد من المختصبن " في مجال الكرة الطائرة والتعلم

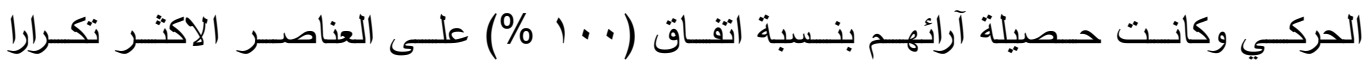
واختباراتها، وعلى النحو الآتي : *- القــوة الانفجاريـة للـساقين : وتـم قياسـها باختبـار القفـز العــودي (لــارجنت) هـن الحركة . (Richard , 1980,96$)$

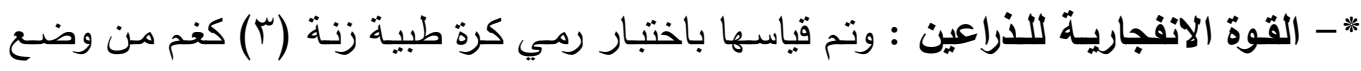
الجلوس على الكرسي • (عثمان ، .99 199 ، 14 (1) .

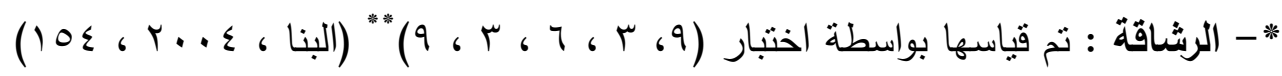
*- مرونـة الاكتـاف : تم قياسـها باختبار يؤدى من وضـع الانبطاح واليدان ممسكتان بمسطرة تكون موازية للارض ويقوم المختبر برفع الذراعين خلفا الى اقصى مسافة مدكنة من دون

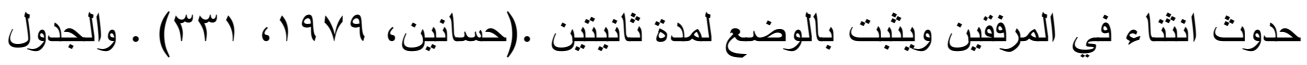

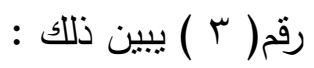

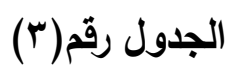

"ا. م. م. د. خالد عبد المجيد/ كلية التربية الرياضية / جامعة الموصل .

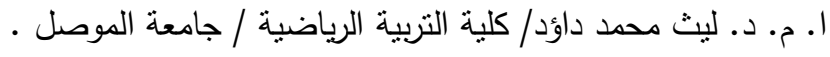

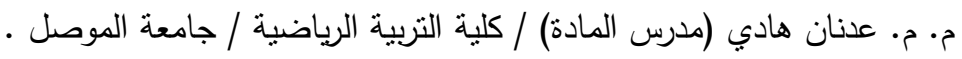

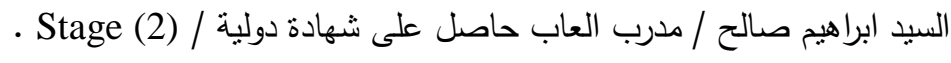

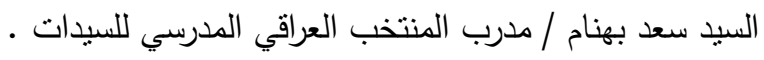
* * اختبار خاص في ملعب الكرة الطائرة 
يبين دلالة الفروق بين مجموعتي البحث في بعض عناصر اللياقة البذنية وإلحركية المختارة

\begin{tabular}{|c|c|c|c|c|c|}
\hline \multirow{2}{*}{ قالمسمة ت } & \multicolumn{2}{|c|}{ التجريبية } & \multicolumn{2}{|c|}{ الضنابطة } & \multirow{2}{*}{ المتغيرات } \\
\hline & $\varepsilon n$ & س - & $\varepsilon n$ & س - س & \\
\hline. .49 & E.Yo & rV.Tr & $\varepsilon . \wedge r$ & rᄉ.ı & القوة الانفجاربة للساقين (سم) \\
\hline $1 . .7$ &..$\top \wedge$ & $\varepsilon .7 t$ & $\cdot . \leqslant V$ & 纟.จ & القوة الانفجارية للذراعين (متر ) \\
\hline $1 . \wedge$. &.$v 4$ & M. &..$Y \wedge$ & $|r . \wedge|$ & الرشاقة (ث) \\
\hline.$M^{\prime}$ & $\varepsilon . .9$ & ro.VY & $\varepsilon .1 \mathrm{~V}$ & M.Y.Y & مرونة الكتفين (سم) \\
\hline
\end{tabular}

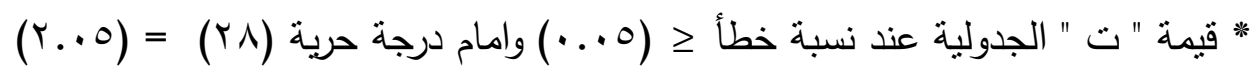

يتبين من الجدول رقم(ץ) وجود فروق ذات دلالة غير معنوية بين مجموعتي البحث في

بعض عناصر اللياقة البدنية والحركية مما يدل على تكافؤ مجموعتي البحث بتلك المتغيرات .

: ب - التصميم التجريبي

استخدم التصميم التجريبي الذي يطلق عليه اسم (تصميم المجموعات المتكافئة ذات الملاحظة البعدية ) فضلا عن (تصميم إنتقال أثز التعلم العمودي والعمودي المعكوس ) وكما هو موضح

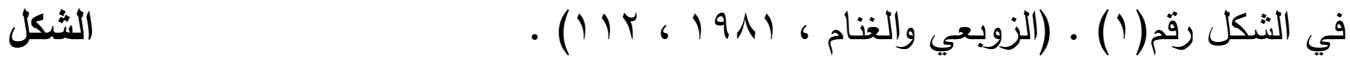

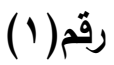

يوضح التصميم التجريبي للبحث

\begin{tabular}{|c|c|c|}
\hline اختبار بعدي & المهمات & المجموعة \\
\hline تحصيل مهاري & الانتقال العمودي + وسائل تعليمية & ص \\
\hline تحصيل مهاري & الانتقال العمودي المعكوس + وسائل تعليمية & $ت$ \\
\hline
\end{tabular}

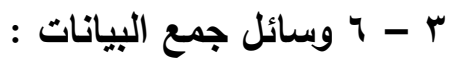

* تحليل محتوى المصادر العلمية .

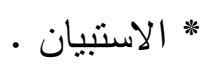

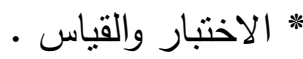

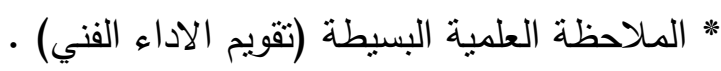

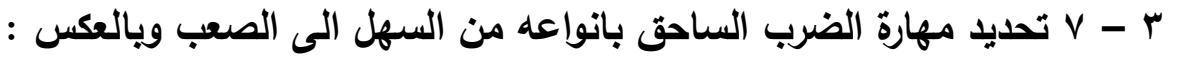


قام الباحثّن باعداد استمارة استنيان (ملحق ץ) يتضمن مهارة الضرب الساحق بانواعه بالكرة الطائرة وتم عرضسه على عدد من المختصين " في مجال الكرة الطائرة والتعلم الحركي لئي وذلك لوضـع تسلسل لتعلم مهارة الضرب الساحق مـن المهارة السهلة الى المهارة الصعبة وبالعكس، وذلك على وفق انتقال أثر التعلم العمودي والعمودي المعكوس، وكانت نسبة اتفاقهم

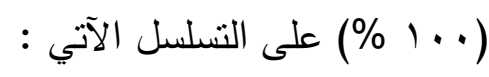

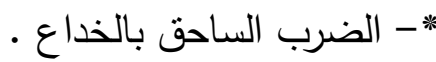

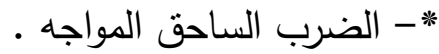

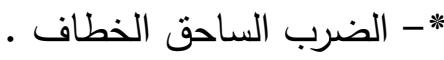

**- الضرب الساحق من المنطقة الخلفية .

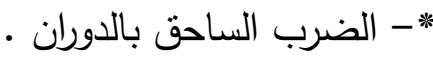

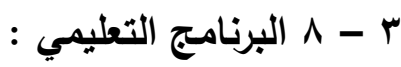

من خـلال الاطلاع على عدد من المصادر العلميـة والابحـاث ذات العلاقة (مطرود،

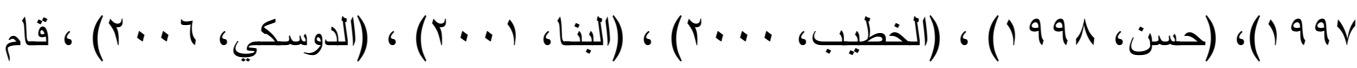
الباحثون باعداد برنامج تعليمي على ضوء المنهج المقرر من الهيئة القطاعية لكليات التربية الرياضية في تعلم دهارة الضرب الساحق بانواعه بالكرة الطائرة، وعلى وفق انتقال اثر التعلم العمودي والعمودي المعكوس، وتم عرض البرنامج على عدد من المختصين "في مجال التعلم

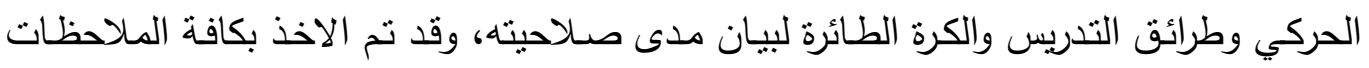

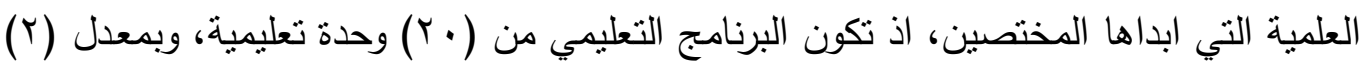
* ا . م. د. خالد عبد المجيد/ كلية التربية الرياضية / جامعة الموصل .

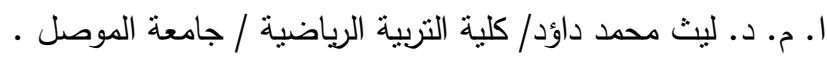

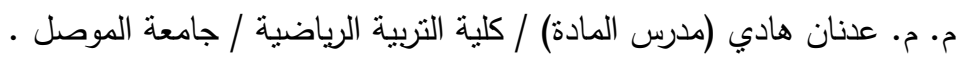

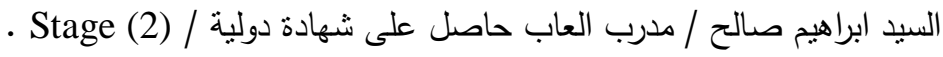

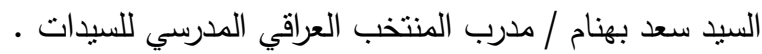

ا. م. د. خالد عبد المجيد/ كلية التربية الرياضية / جامعة الموصل .

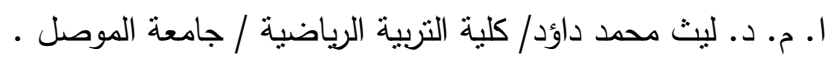

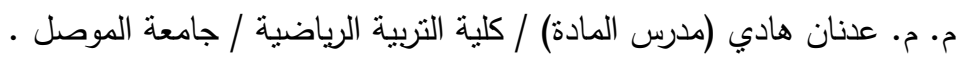

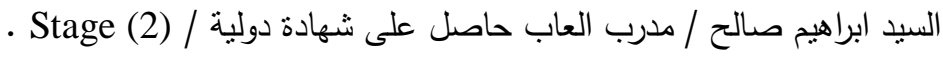

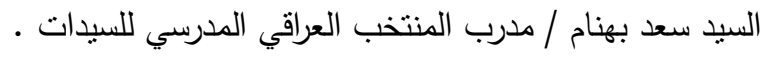

$1 \cdot 1$ 
وحدتين تعليمية لكل مجموعة وبزمن (•9) دقيقة للوحدة التعليمية، حيث استغرق تتفيذ البرنامج

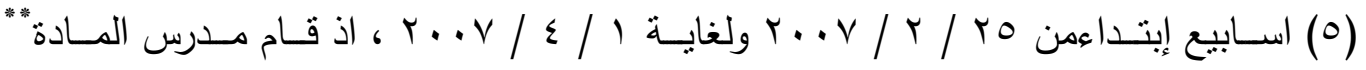

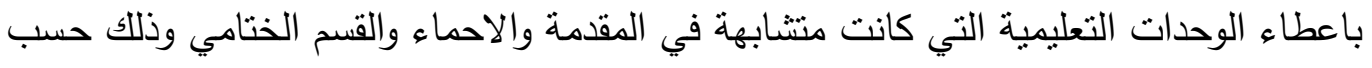
جدول الدروس الاسبوعي، اما الاختلاف فكان في القسم الرئيس في تسلسل المهارات من السهلة

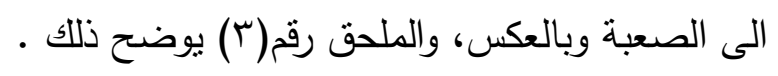

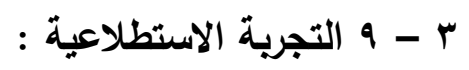

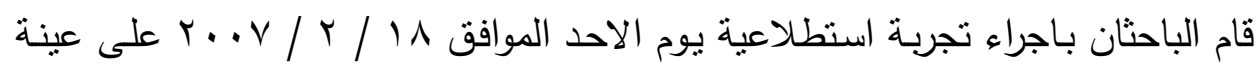

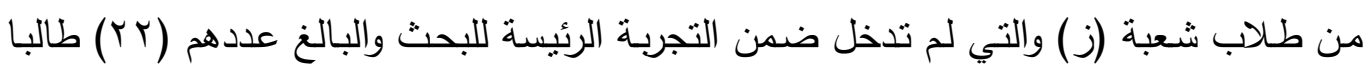

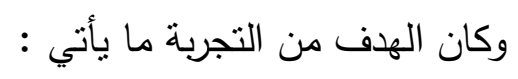

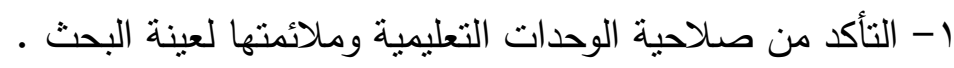

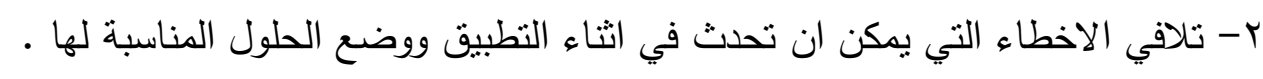

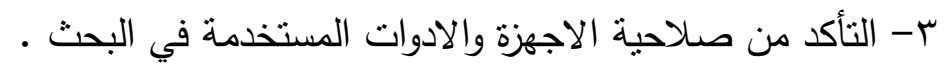

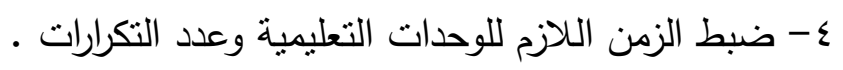

وكان من نتائج التجربة الاستطلاعية هو تكوين صورة واضحة عن طبيعة العمل وكيفية

• النطبيق

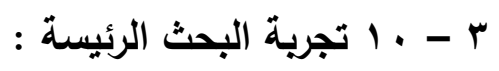

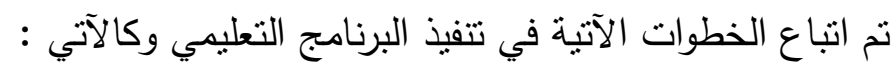

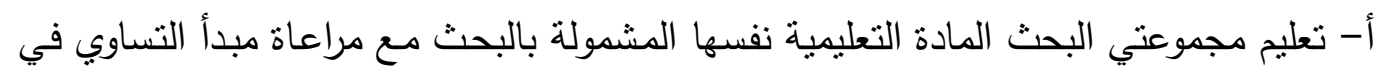

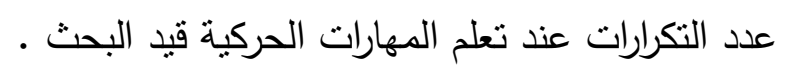

ب- طبقت المجموعـة الضابطة انتقال اثر التعلم العهودي (مـن المهارة السهلة الـى المهات المهارة

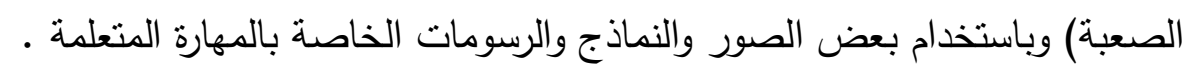

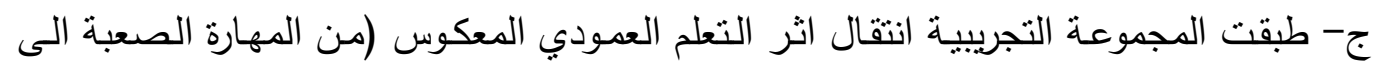

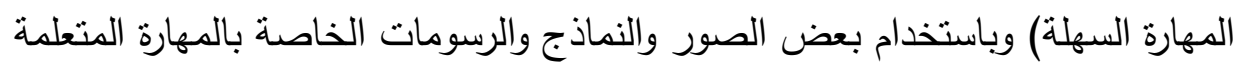

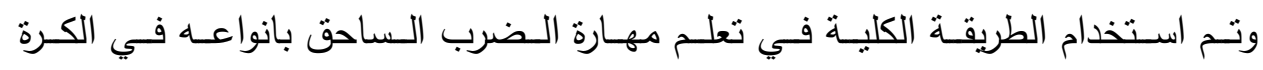

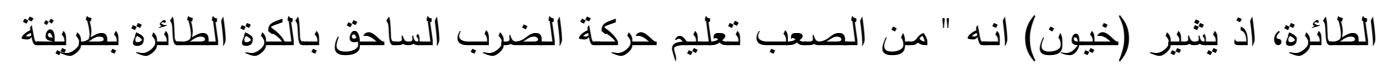

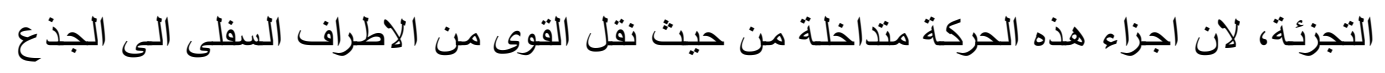

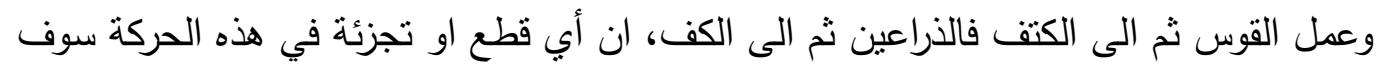

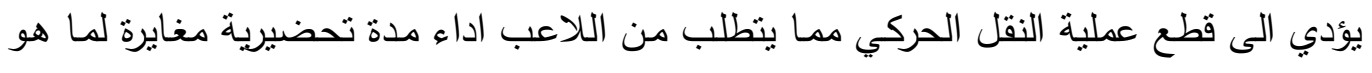


موجود لغرض ايجاد القوة الكافية لـلاداء لتعويض عملية نقل القوة من الجذع الى الكف " .

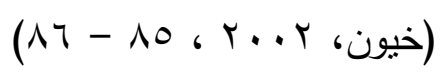

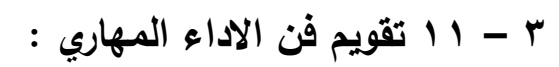

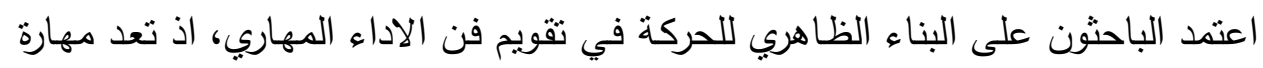

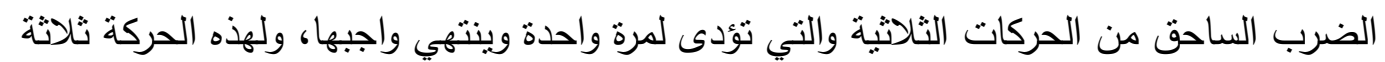

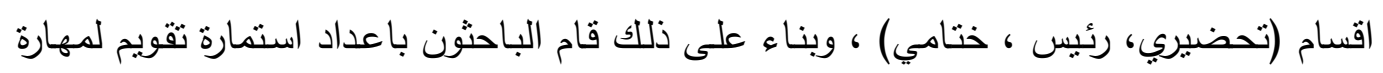

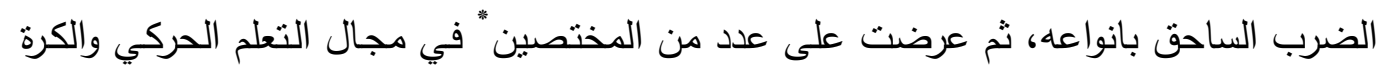

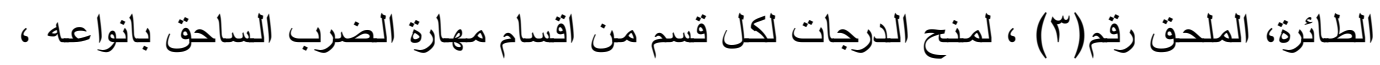

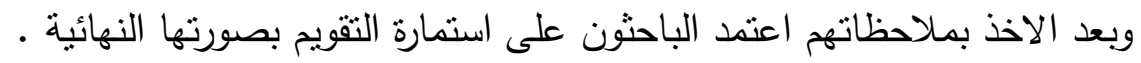

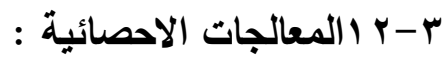

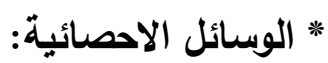

استخدم الباحثان الوسائل الاحصائية والمعادلات الخاصة بحساب انتقال اثر التعلم الآتية :

$$
\text { * - الاسط الحساف المعياري . }
$$

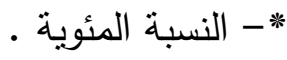

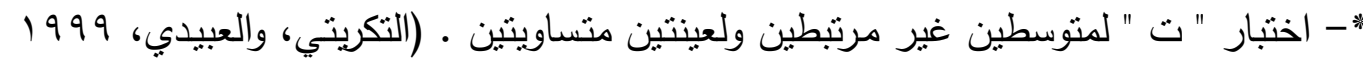

$$
\text { • (rVq - ). ، }
$$

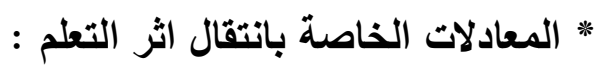

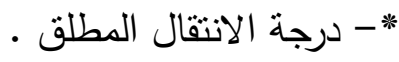

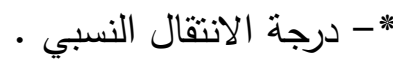

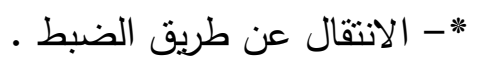

* - الانتقال عن طريق القياس المنوازن •

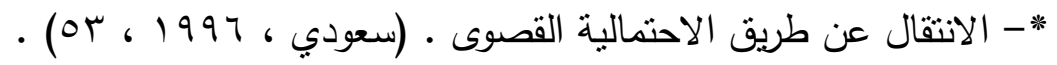

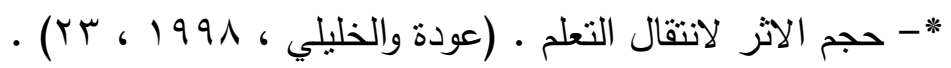

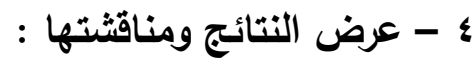

؛ - 1 عرض النتائج :

* عرض نتائج اختبار " ت " : بين مجموعتي البحث في تعلم مهارة الضرب الساحق بانواعه

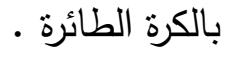

* المختصون نفسهم السابق ذكرهم في البحث .

11 


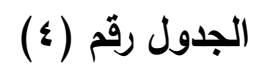

يبين دلالة الفروق بين مجموعتي البحث في الاختبار البعدي

في تعلم مهارة الضرب الساحق بالكرة الطائرة

\begin{tabular}{|c|c|c|c|c|c|}
\hline \multirow{2}{*}{ قالمسية " ت " } & \multicolumn{2}{|c|}{ الضابطة } & \multicolumn{2}{|c|}{ التجريبية } & \multirow{2}{*}{ انواع الضرب الساحقى ل المعالم الاحصائية } \\
\hline & $\varepsilon n$ & 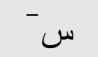 & $\varepsilon n$ & 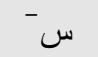 & \\
\hline "r.乏1 & 1.r & $V .7$ &. .90 & 7.11 & الضرب الساحق بالخداع \\
\hline "T.T & $\cdot . \wedge \wedge$ & V.乏 & $\cdot . \leqslant V$ & 7.04 & الضرب الساحق المواجه \\
\hline "T.TY & $1 . r \leq$ & 7.7 & $.7 \mathrm{~V}$ & 0.74 & الضرب الساحق الخطاف \\
\hline "r.V. & $.9 r$ & T.rT & $\because V V$ & $0 . r \varepsilon$ & الضرب الساحق من الملعب الخلفي \\
\hline $0.1 \mathrm{~V}$ &. .07 & $0.1 \mathrm{~V}$ & דיח. & E.rq & الضرب الساحق بالدوران \\
\hline
\end{tabular}

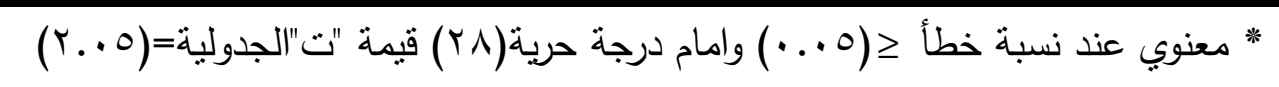

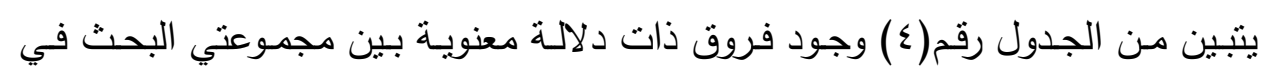

الاختبار البعدي في جميع انواع مهارة الضرب الساحق بالكرة الطائرة .

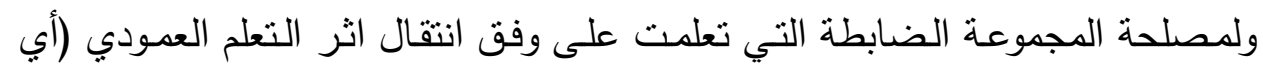

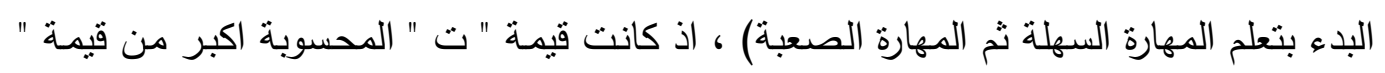

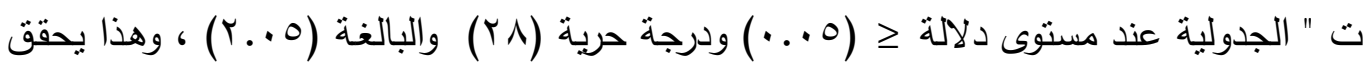

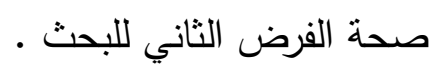

* عرض نتائج انتقال اثر التعلم العمودي و العـودي المعكوس في تعلم مهارة الضرب الساحق بالكرة الطائرة

يتبين من الجدول رقم(0) ان الانتقال كان سلبياً في جميع انواع انتقال اثر التعلم ، اذ كانت قيم

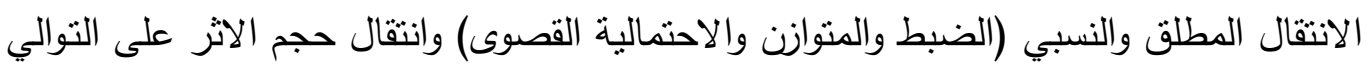
وكما يأتي : الانقال الفطل

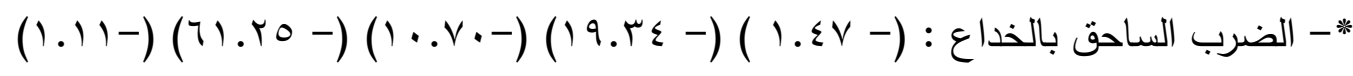

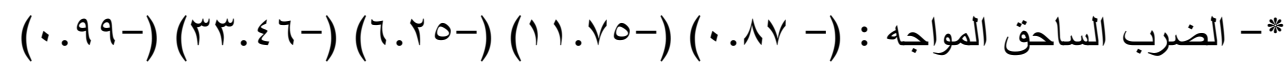

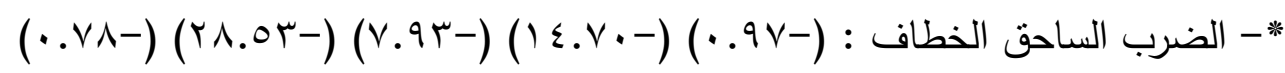




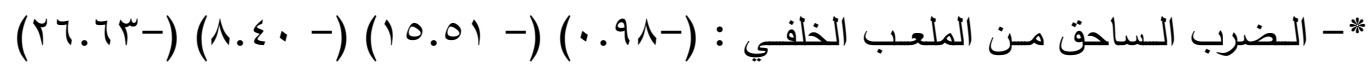
(1... V-)

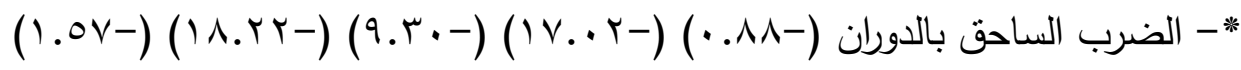
وهذا يعني ان استخدام الاسلوب العمودي لانتقال اثر التعلم باستخدام الوسائل التعليمية التانية

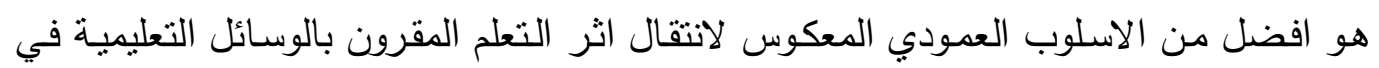

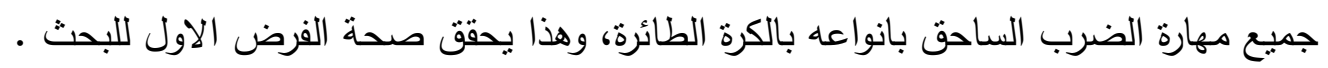

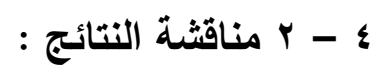

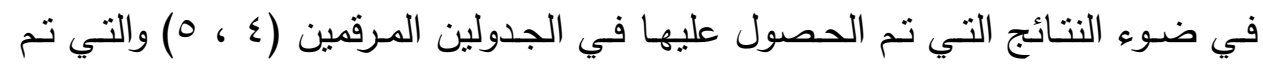

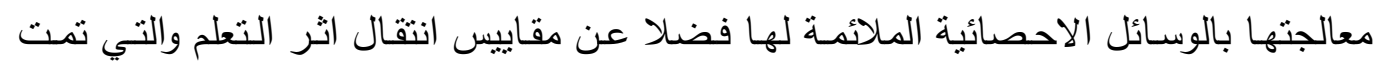

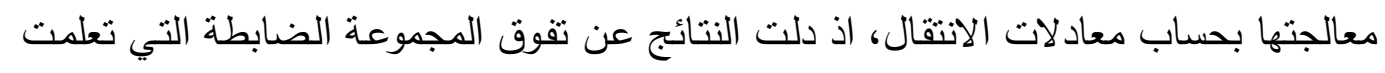

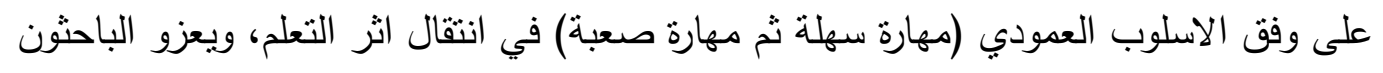

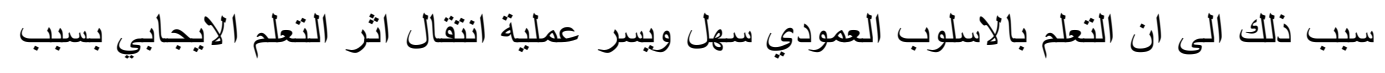

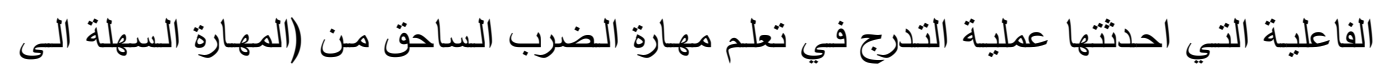

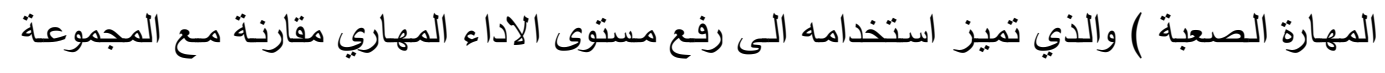
التجريبية التي تعلمت على وفق الاسلوب العمودي المعكوس (من المهارة الصعبة الى المهارة

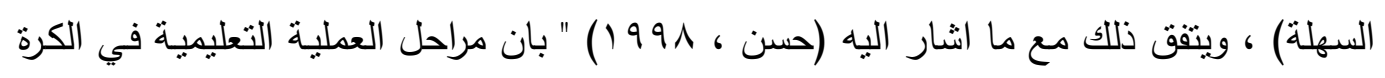

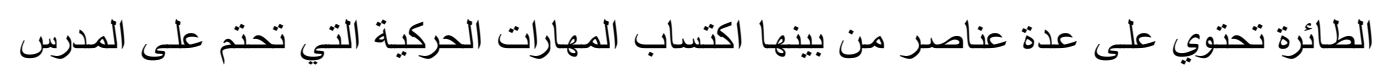

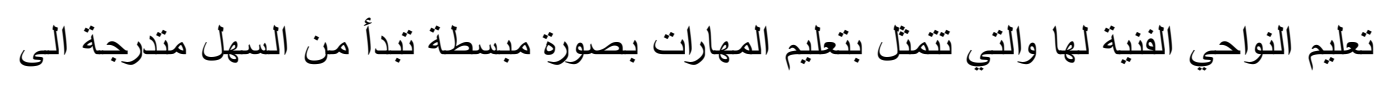

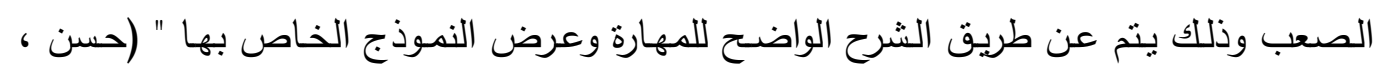

- ( $r \leq 61991$

ويضيف الباحثون الى ان البدء بتعلم المهارة السهلة والنجاح الذي تحقق لدى المتعلمين

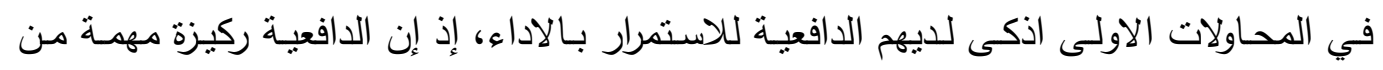

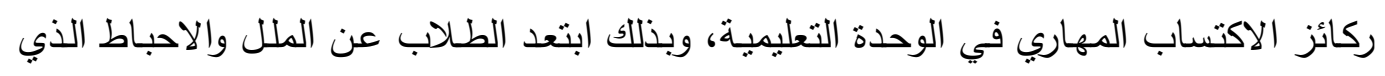

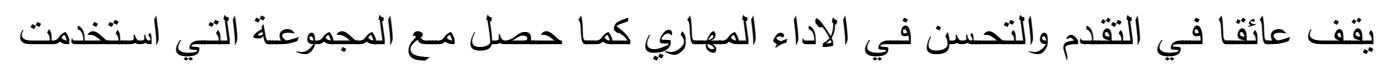
الاسلوب العمودي المعكوس، فضلا عن ان الوسـائل التعليميـة من (رسوم ، نمـاذج ، صسور )

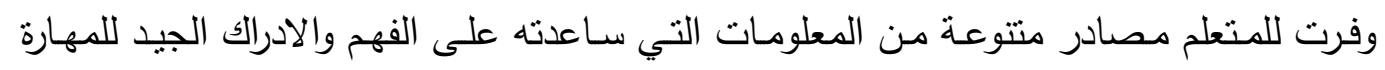

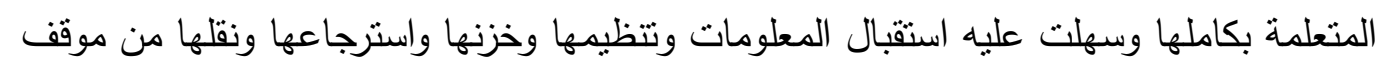

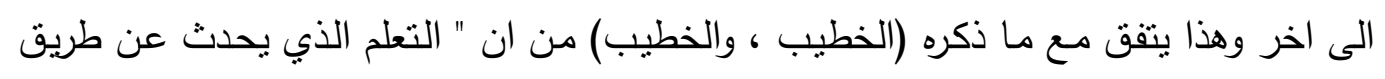

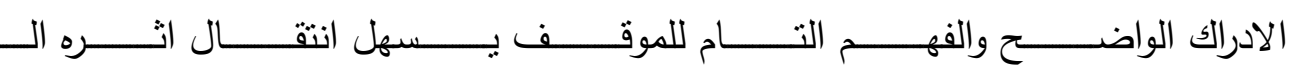

المواقف الجديدة(الخطيب ، والخطيب ، 1917 ( 190 ، 


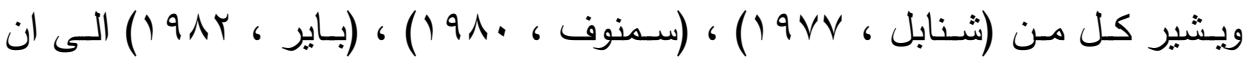

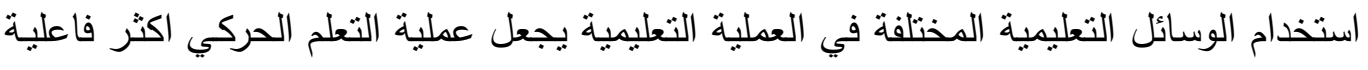

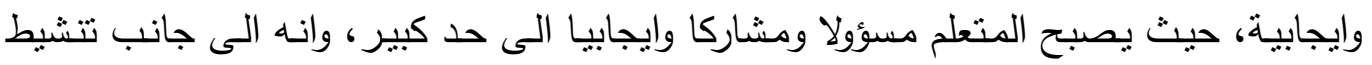

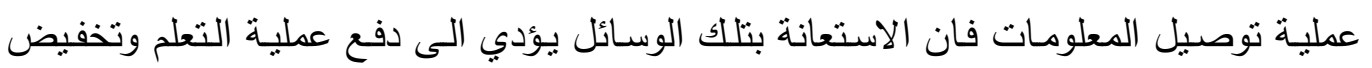

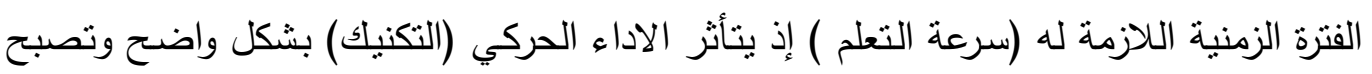
مواصفات الحركة اكثر دقة واتقانا، ولا يتوقف دور الوسائل التعليمية عند هذا الحد، بل يتعدى الدى لئه الى اساس العملية التعليمية وهو التصور الحركي فتعمل على بنائه وتطويره عند الفرد المتعلم .

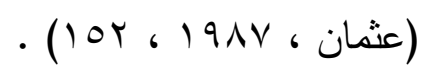

ويرى الباحثون ان عملية التدرج في الانتقال من المهارة السهلة (عمودي) الى المهارة

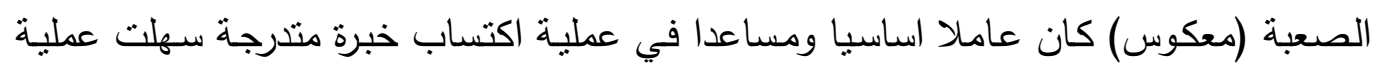

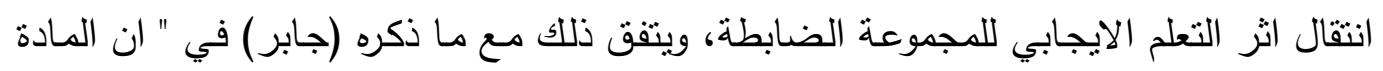

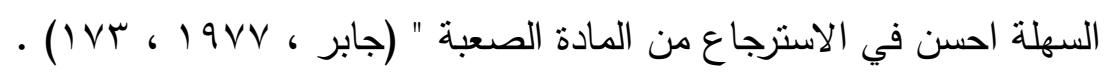

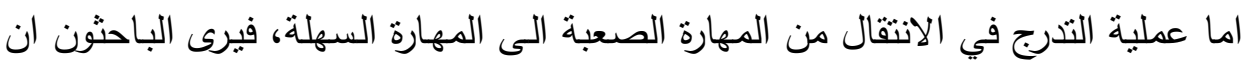

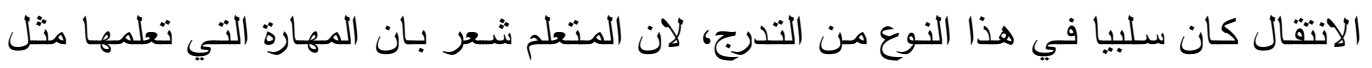

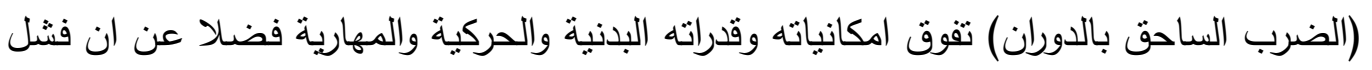

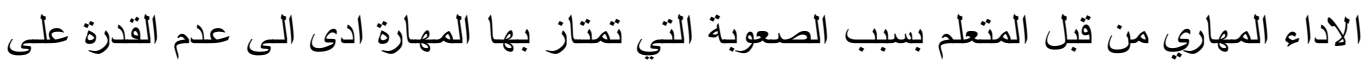

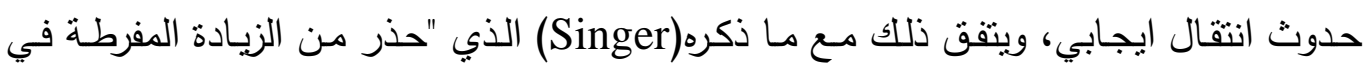

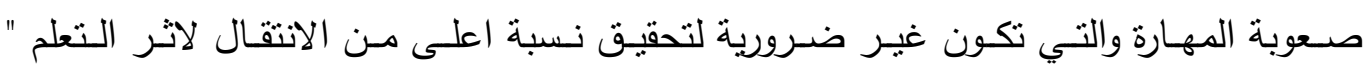
· ( Singer, 1975, 448)

ويتفق الباحثان مع ما ذكره (محجوب) بانه " من العوامل التي تؤدي الى تسهيل انتقال

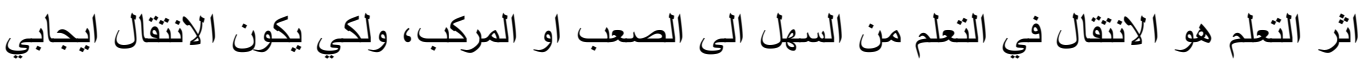
يجب ان يبدأ بتعلم المهارات الاساسية المختلفة اولا ثم الانتقال الى الميادين التطبيقية او الانتقال

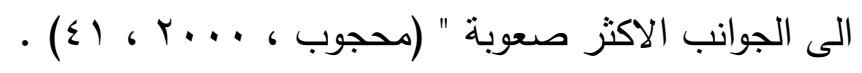

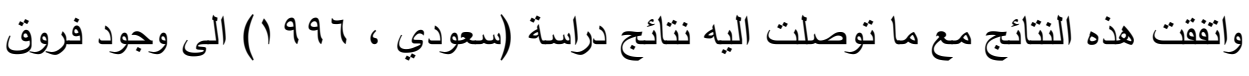

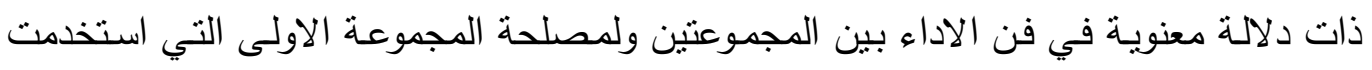

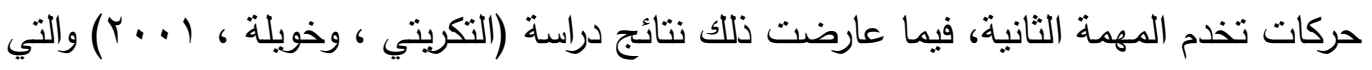
اثشارت الى ان المجموعة الاولى التي بدأت بالمهمة الصعبة ثم السهلة (العمودي المعكوس) حققت افضل انتقال ايجابي في فن اداء قذف الثقل مقارنة مع المجموعتين الثانية والثالثة .

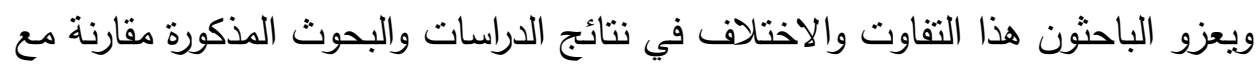
ما توصلت اليه نتائج الدراسة الحالية ، الى طبيعة ونوع المهارة المتعلمة ، وهذا يتفق مع ما ذكره 
كل من (محجوب ، ومحمود) " من ان طبيعة المادة المتعلمة ونوع تلك المادة هي من العوامل التي تؤثر على عملية انتقال اثر التعلم الايجابي " (محجوب ، . . . ، ، . ع) ، (محمود ، . (100، 1917

0 - - الاستنتاجات والتوصيات

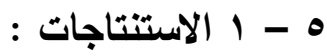

*- حققت المجموعـة الضابطة التي بـأت بالمهــة السهلة ثم الصعبة (الانتقال العهودي ) والمقرون بالوسائل التعليمية افضل انتقال ايجابي في تعلم مهارة الضرب الساحق بانواعه

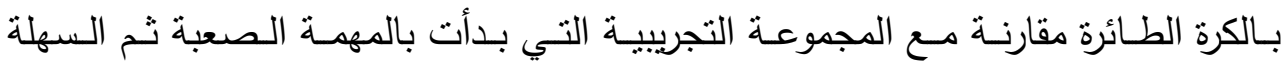

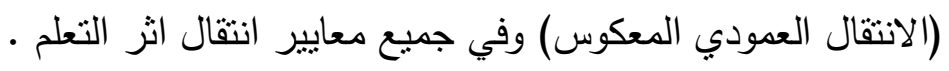

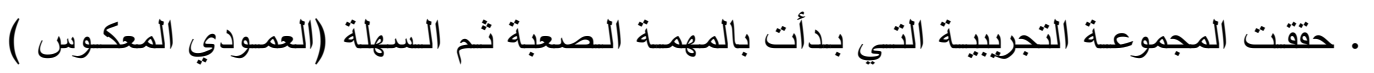

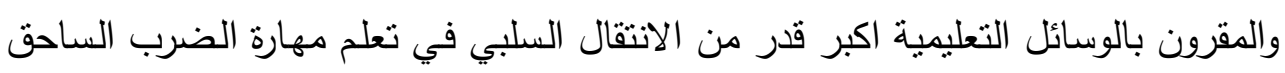

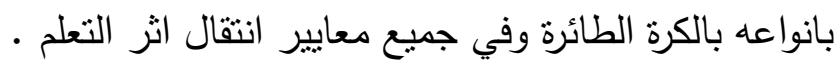
* - وجود فروق ذات دلالة معنوية بين مجموعتي البحث ولمصلحة المجموعة الضابطة التي لئي

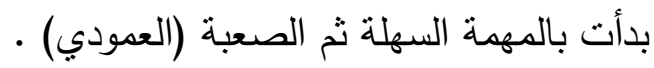

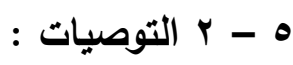

ـ البدء بتعليم المهيات السهلة ثم المهيات الصعبة (الانتقال العهودي) وباستخدام الوسـائل التعليمية المساعدة في مهارة الضرب الساحق بانواعه بالكرة الطائرة .

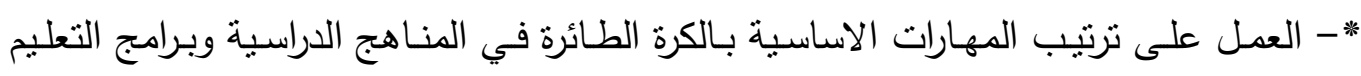

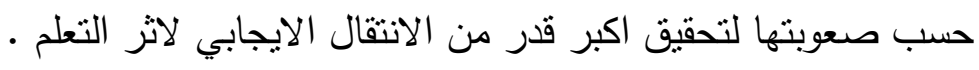

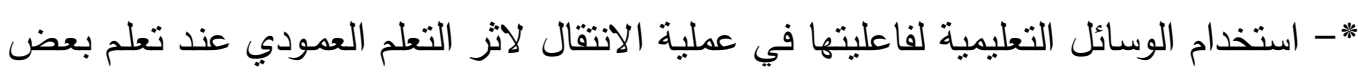
المهارات الاساسية بالكرة الطائرة .

\section{المصادر العربية والانكليزية}

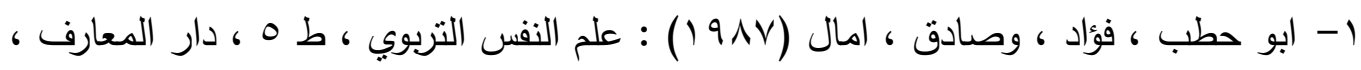

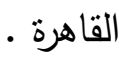

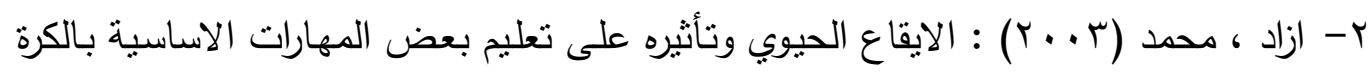

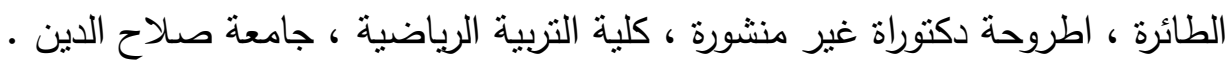

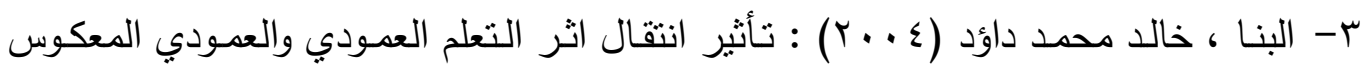

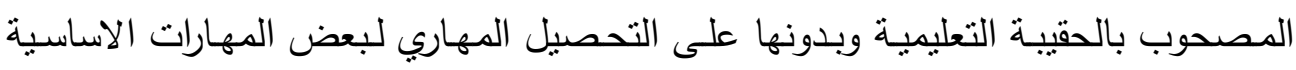

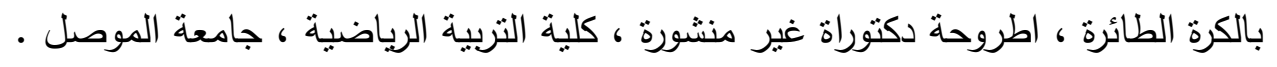




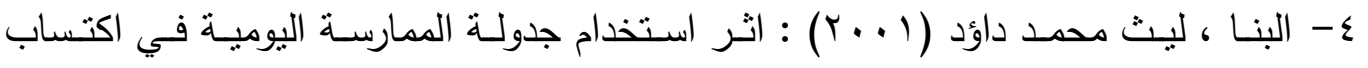
واحتفاظ فن اداء ودقة بعض الارسالات السهلة والصعبة بـالكرة الطائرة ، اطروحة دكتوراه

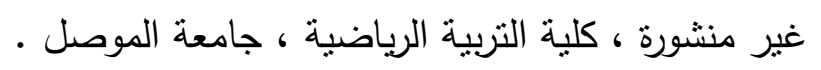
0- التكريتتي ، وديـع ياسـين ، والعبيـدي ، حسن محمــ (999 1) : التطبيقـات الاحـصائية واستخدامات الحاسوب في بحوث التربية الرباضية ، دار الكتب للطباعة والنشر ، جامعة الموصل

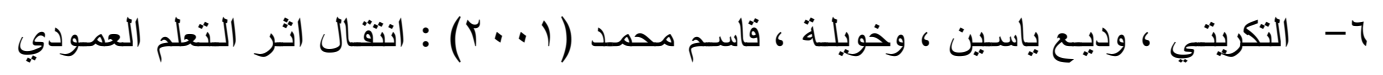
والعمودي المعكوس والمتزامن واثره في فن اداء قذف الثقل ، بحث منشور في مجلة الرافدين

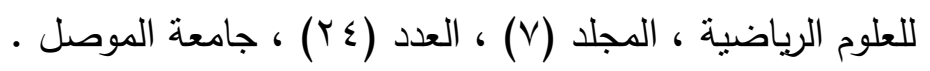

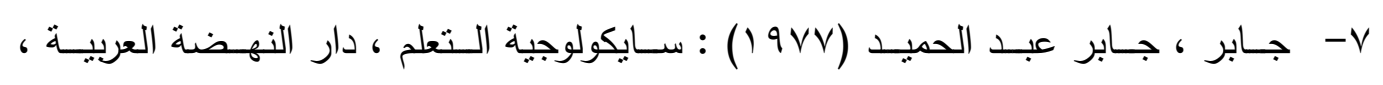
• (القاهرة ، مصر

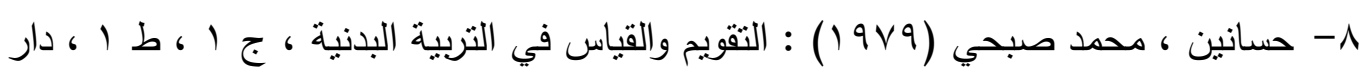
الفكر العربي ، القاهرة .

9- حسانين ، محمد صبحي ، وعبد المنعم ، حمدي (9AV) ( I ) : التقويم والقياس في التربية البدنية ، ط ب ، دار الفكر العربي ، القاهرة .

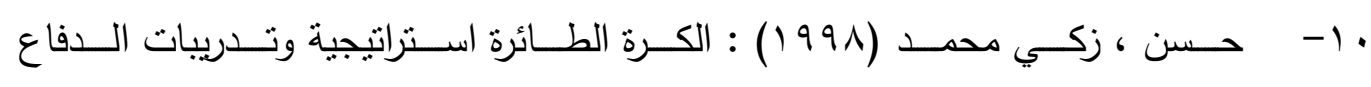

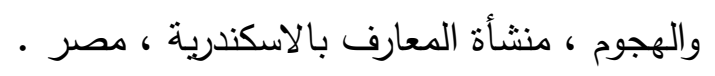

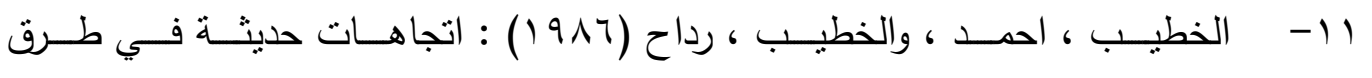

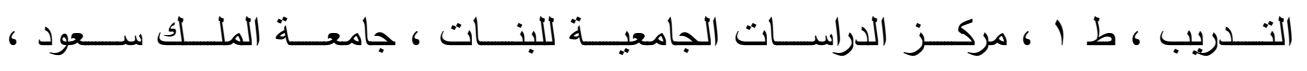

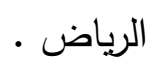

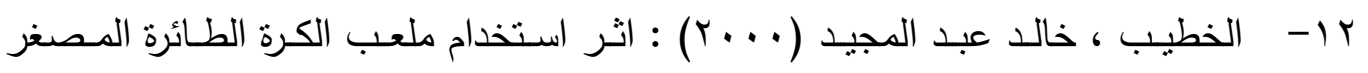
بجرعـات مختلفـة في تعلـم بعض المهارات الاساسـية وتطـوير القدرات البدنيـة والحركيـة الخاصـة بـالكرة الطـائرة ، اطروحة دكتوراة غيـر منشورة ، كليـة التربيـة الرباضية ، جامعـة

$$
\text { الموصل - الماصل }
$$

rا - الخولي ، امين انور ، وراتب ، اسـامة كامل ، (YA I ) : التربية الحركية ، دار الفكر

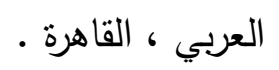

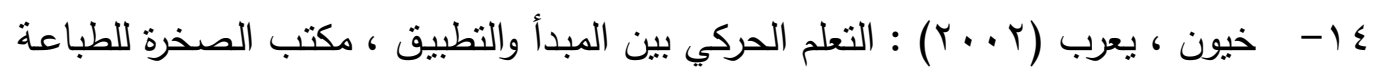

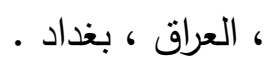




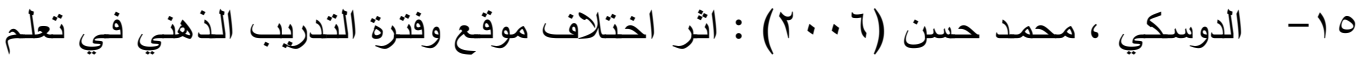
مهارة الضرب الساحق بانواعه بالكرة الطائرة ، اطروحة دكتوراة غير منشورة ، كلية التربية الرياضية ، جامعة الموصل .

7 ا - الزوبعي ، عبد الجليل ، والغنام ، محمد احمد (1919 ()) : مناهج البحث في التربية ، ج

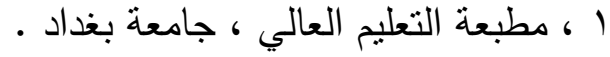

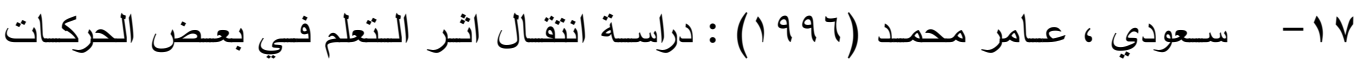
التمهيدية على اجهزة الجمناستيك ، اطروحة دكتوراة غير منشورة ، كلية التربية الرياضية ،

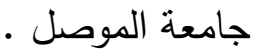

1 ا- سـلامة ، عبد الحافظ ، (9911) : مدخل الى تكنولوجيا التعليم ، ط ب دار الفكر ، - الاردن

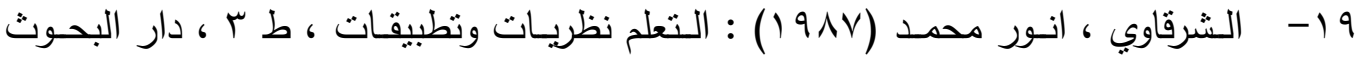
العلمية ، الكوبت . مبت

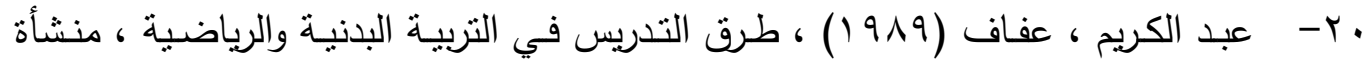
المعارف ، الاسكندرية .

ا Y- عثـان ، سـيد ، والشرقاوي ، انـور محمـد (9VV I ) : التعلم وتطبيقاتـه ، دار الثقافـة للطباعة والنشر ، القاهرة .

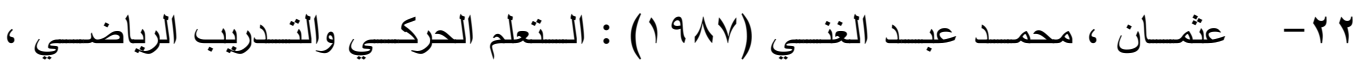
ط ا ، دار القلم للنشر والتوزيع ، الكوبت .

بr- _ـ ( • 199) : موسـوعة العـاب القوى ، تكنيـك ، تدريب ، تعليم ، تحكيم ، مطبعـة الفيصل ، دار القلم للنشر والتوزيع ، الكويت .

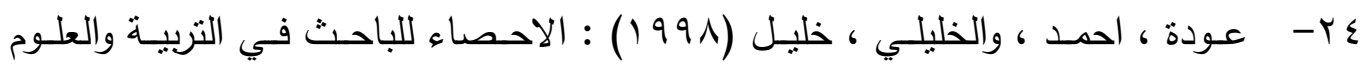
الانسانية ، دار الفكر ، عمان ، الاردن • الفي

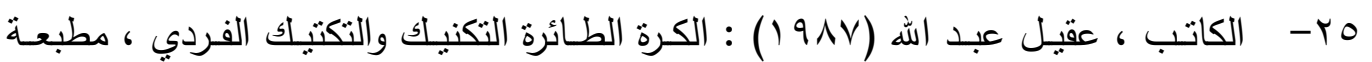
التعليم العالي ، بغداد . צr- كراجة ، عبد القادر (99V (19) : سيكولوجية التعلم ، ط ا ، دار الباوزدي للنشر والتوزيع

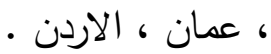

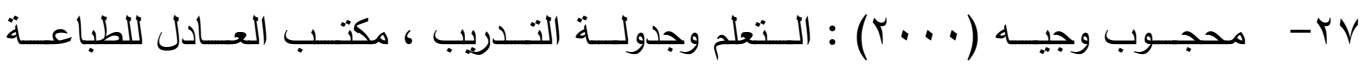

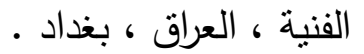
^ץ- - محمـود ، ابـراهيم وجيـه (917 1) : التتحلم (اسـسه ونظرياتـه وتطبيقاتـه) ، مكتبـة الانجلو مصرية ، القاهرة . 
9 - مطرود ، حازم احمد (99V ( ) : اثر استخدام اساليب مختلفة في تتظيم محتوى منهج

الكرة الطائرة في مستوى التحصيل والاحتفاظ المعرفي والحركي ، اطروحة دكتوراة غير

$$
\text { منشورة ، كلية التربية الرياضية ، جامعة الموصل . }
$$

30- Cohan, Robert (1997) : Power Volley Ball drills, united state volley Ball Association, Holleywood, C. A. , U. S. A.

31- Mouly, George (1973) : Psychology for effective teaching, third edition, U. S. A.

32- Mourice, Taylor, (1997) : Transfer of learning, planning workplace Education programs with active Publication, England.

33- Richard, H, Cox (1980) : Teaching Volley Ball, Burgess Publishing Company, Minesota, U. S. A.

34- Schmidt, Richard (1991) : Motor learning and performance from principles to practice, Human kinetics champion, illinoes.

35-Singer, R. A. (1975) : Motor Learning and Human Performance, $2^{\text {nd }}$ edition, Macmillar Publishing Company, U. S. A. 


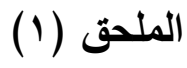

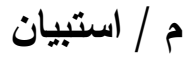

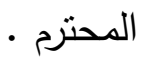

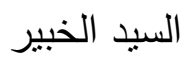

سيقوم الباحثون باجراء البحث الموسوم " انتقال اثر التعلم العمودي والعمودي المعكوس

باستخدام بعض الوسائل التعليمية في تعلم مهارة الضرب الساحق بالكرة الطائرة "

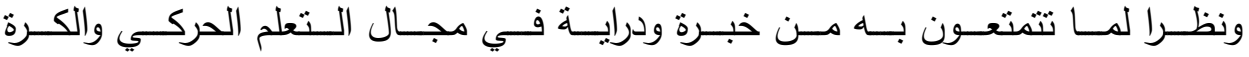

الطائرة ، برجى تحديد اهم عناصر اللياقة البدنية والحركية الخاصة بالبحث مع اختباراتها وذلك

بوضع علامة ( ـ) امام العنصر الاكثز اهمية والاختيار المناسب له ، مع التقدير ل...

\begin{tabular}{|c|c|c|}
\hline الاختبار المناسب & العناصر & $ت$ \\
\hline & القوة الانفجارية للذراعين & 1 \\
\hline & القوة الانفجارية للرجلين & r \\
\hline & الرشاقة . & r \\
\hline & مرونة الاكتاف . & $\varepsilon$ \\
\hline & مرونة العمود الفقري . & 0 \\
\hline & التحمل العضلي . & 7 \\
\hline & الدقة . & v \\
\hline & ذ التوافق . & $\wedge$ \\
\hline
\end{tabular}

الباحثون 


\section{الملحق (ץ) (

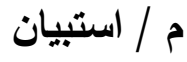

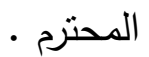

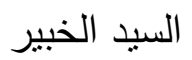

سيقوم الباحثون باجراء البحث الموسوم " انتقال اثر التعلم العمودي والعمودي المعكوس

باستخدام بعض الوسائل التعليمية في تعلم مهارة الضرب الساحق بالكرة الطائرة " .

ولكونكم من ذوي الخبرة والاختصاص في هذا المجال يرجى التفضل بتصنيف مهارة

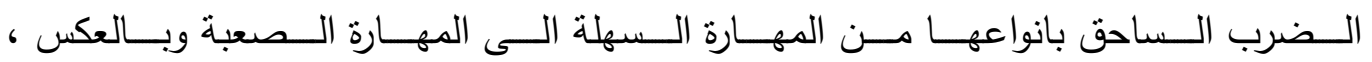

مع التقدير ...

\begin{tabular}{|c|c|c|c|}
\hline من المهارة الصعبة الى المهارة السهلة & من المهارة السهلة الى المهارة الصعبة & انواع الضرب الساحق & $ت$ \\
\hline & & الضرب الساحق بالخداع & 1 \\
\hline & & الضرب الساحق الخطاف & r \\
\hline & & الضرب الساحق المواجه & r \\
\hline & & الضرب الساحق من المنطقة & $\varepsilon$ \\
\hline & & الضرب الساحق بالدوران & 0 \\
\hline
\end{tabular}

الباحثن

119 


\section{ملحق (广)}

نموذج للتنرج بتعليم الضرب الساحق من المهارة السهلة الى المهارة الصعبة ، وبالعكس

باستخدام بعض الوسائل التعليمية بالكرة الطائرة (وفقا لتسلسل المهارات قبد البحث)

القسم الرئيس : (V•) دقيقة

\begin{tabular}{|c|c|}
\hline المحتوى & 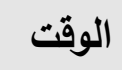 \\
\hline اعادة المهارة السابقة . & د) \\
\hline شرح وعرض المهارة امام الطلاب من قبل مدرس المادة . & د. \\
\hline مشاهدة بعض الصور والرسومات الخاصة بالمهارة . & د o \\
\hline اداء المهارة بدون كرة . & د o \\
\hline من الحائط . . ادهارة بكرات على الحائط بحيث تضرب على بعد ب م على الارض وترتد & د \\
\hline من الحائط . . ادهارة بالكرة على الحائط بحيث تضرب على بعد ؟ م على الارض وترتد & د \\
\hline اداء المهارة بدون كرة على الثبكة . & د \\
\hline اداء المهارة بالكرة مع خفض الثبكة . & دo \\
\hline اداء المهارة مع الزميل على الثبكة . & د \\
\hline اداء المهارة مع الزميل مع رفع مستوى الثبكة . & د \\
\hline اداء المهارة على الثبكة والضرب على مناطق مختلفة في الملعب . & د \\
\hline اداء المهارة على الثبكة والضرب على مناطق محددة مسبقا ـ & د O \\
\hline
\end{tabular}

